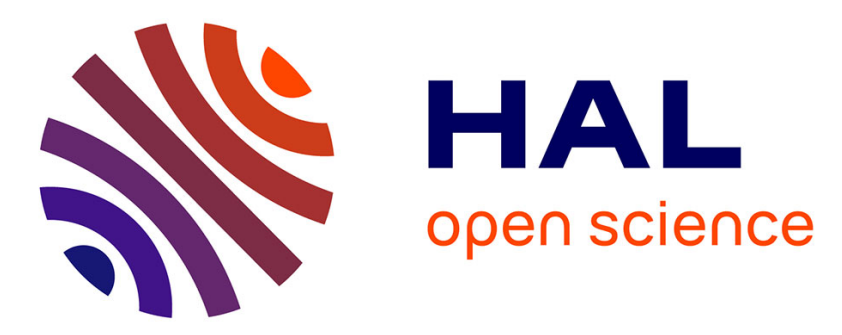

\title{
Control of shortwave radiation parameterization on tropical climate SST-forced simulation
}

Julien Crétat, Sébastien Masson, Sarah Berthet, Guillaume Samson, Pascal

Terray, Jimy Dudhia, Françoise Pinsard, Christophe Hourdin

\section{To cite this version:}

Julien Crétat, Sébastien Masson, Sarah Berthet, Guillaume Samson, Pascal Terray, et al.. Control of shortwave radiation parameterization on tropical climate SST-forced simulation. Climate Dynamics, 2016, 47 (5), pp.1807-1826. 10.1007/s00382-015-2934-1 . hal-01262857

\section{HAL Id: hal-01262857 \\ https://hal.sorbonne-universite.fr/hal-01262857}

Submitted on 27 Jan 2016

HAL is a multi-disciplinary open access archive for the deposit and dissemination of scientific research documents, whether they are published or not. The documents may come from teaching and research institutions in France or abroad, or from public or private research centers.
L'archive ouverte pluridisciplinaire HAL, est destinée au dépôt et à la diffusion de documents scientifiques de niveau recherche, publiés ou non, émanant des établissements d'enseignement et de recherche français ou étrangers, des laboratoires publics ou privés. 
3 Control of shortwave radiation parameterization on tropical climate SST-forced simulation

Julien Crétat $^{1}{ }^{*}$, Sébastien Masson ${ }^{1}$, Sarah Berthet $^{1,2}$, Guillaume Samson ${ }^{1,2}$, Pascal Terray ${ }^{1,3}$, Jimy Dudhia ${ }^{4}$, Françoise Pinsard ${ }^{1}$, Christophe Hourdin ${ }^{1}$

10

11

${ }^{1}$ Sorbonne Universités (UPMC, Univ Paris 06)-CNRS-IRD-MNHN, LOCEAN Laboratory, 13 IPSL, Paris, France

${ }^{3}$ Indo-French Cell for Water Sciences, IISc-NIO-IITM-IRD Joint International Laboratory,

Revised 10/06/2015

$31 *$ Corresponding author address: Julien Crétat

32 julien.cretat@locean-ipsl.upmc.fr 


\section{Abstract}

SST-forced tropical-channel simulations are used to quantify the control of shortwave (SW) parameterization on the mean tropical climate compared to other major model settings (convection, boundary layer turbulence, vertical and horizontal resolutions), and to pinpoint the physical mechanisms whereby this control manifests. Analyses focus on the spatial distribution and magnitude of the net SW radiation budget at the surface (SWnet_SFC), latent heat fluxes, and rainfall at the annual timescale. The model skill and sensitivity to the tested settings are quantified relative to observations and using an ensemble approach.

Persistent biases include overestimated SWnet_SFC and too intense hydrological cycle. However, model skill is mainly controlled by SW parameterization, especially the magnitude of SWnet_SFC and rainfall and both the spatial distribution and magnitude of latent heat fluxes over ocean. On the other hand, the spatial distribution of continental rainfall (SWnet_SFC) is mainly influenced by convection parameterization and horizontal resolution (boundary layer parameterization and orography).

Physical understanding of the control of SW parameterization is addressed by analyzing the thermal structure of the atmosphere and conducting sensitivity experiments to $\mathrm{O}_{3}$ absorption and SW scattering coefficient. SW parameterization shapes the stability of the atmosphere in two different ways according to whether surface is coupled to atmosphere or not, while $\mathrm{O}_{3}$ absorption has minor effects in our simulations. Over SST-prescribed regions, increasing the amount of SW absorption warms the atmosphere only because surface temperatures are fixed, resulting in increased atmospheric stability. Over land-atmosphere coupled regions, increasing SW absorption warms both atmospheric and surface temperatures, leading to a shift towards a warmer state and a more intense hydrological cycle. This turns in reversal model behavior between land and sea points, with the SW scheme that simulates greatest SW absorption producing the most (less) intense hydrological cycle over land (sea) points. This demonstrates strong limitations for simulating land/sea contrasts in SST-forced simulations.

Keywords: latent heat fluxes - physical parameterizations - radiative budget - rainfall shortwave radiation schemes - tropical-channel simulations 


\section{Introduction}

State-of-the-art global and regional climate models (GCMs and RCMs; see Table 1 for acronyms) used for coordinated projects such as the Climate Model Intercomparison Project Phase 5 (CMIP5) and the Coordinated Regional Downscaling Experiment (CORDEX) struggle in simulating tropical climate. This is evidenced by large model biases and intermodel spread in simulating the radiative budget of the Earth system (e.g., Kothe et al. 2010; Wang and Su 2013; Li et al. 2013; Wild et al. 2013, 2015; Pessacg et al. 2014). The primary atmospheric reason involves difficulty in accounting for sub-grid processes in GCMs and RCMs. Furthermore, the choice of physical parameterizations induces large uncertainties in simulations (e.g., Flaounas et al. 2011; Pohl et al. 2011; Crétat et al. 2012; Hourdin et al. 2013; Lim et al. 2015; Raktham et al. 2015), and the physical package performing best at a given resolution does not necessarily perform better at higher resolution (e.g., Wehner et al. 2014). While a large body of literature focuses on sensitivity and uncertainties induced by convection $(\mathrm{CU})$, planetary boundary layer (PBL), and microphysics (MP) parameterizations in the tropics, the influence of shortwave (SW) and longwave (LW) radiation parameterizations remains poorly documented.

Morcrette et al. (2008) evaluate the effects of radiation parameterization on climate and weather simulated by the Integrated Forecasting System GCM by comparing two radiation packages. The new "McRad" package outperforms the previous radiation package for most parameters and temporal scales, mainly because of improved cloud-radiation interactions. The added value of the McRad package is significant in the tropics due to a better representation in the vertical distribution of diabatic heating.

$\mathrm{Xu}$ and Small (2002) investigate the influence of two CU and three SW/LW schemes on intraseasonal variability of the North American Monsoon System simulated by the FifthGeneration Mesoscale Model coupled with the Oregon State University Land Surface Model (LSM). They show that (i) the spread induced by the model physics for simulating rainfall is greater than that induced by model internal variability, (ii) the model skill strongly varies according to the $\mathrm{CU}-\mathrm{SW} / \mathrm{LW}$ combinations, and (iii) radiation schemes including feedbacks between condensation and the water content of clouds perform best.

Li et al. (2015) explore the influence of radiation physics on the simulation of the West African Monsoon in the Weather Research and Forecasting (WRF) - Community Land Model framework. Again, radiation schemes significantly modulate the rainfall pattern and associated dynamics, through modifying the meridional thermal gradient between the Sahara 
desert and the Guinean coastline.

These studies highlight tremendous sensitivity of weather and climate to radiation package, but do not assess the control exerted by each of its components (i.e., SW and LW parameterizations) and/or do not discuss the relative influence of radiation parameterizations compared to that of the other physical parameterizations. Pohl et al. (2011) quantify uncertainties in simulating the seasonal mean atmospheric water cycle in equatorial East Africa with the WRF model. They perform sensitivity tests to the model physics (CU, MP, PBL, SW, LW schemes, and LSM), land-use categories, lateral forcing data, and domain geometry. They find that SW parameterization is much more critical than LW parameterization and exerts the largest influence on rainfall, far beyond the influence of $\mathrm{CU}$ parameterization. Similar results are obtained for seasonal rainfall in the southwest of Western Australia (Kala et al. 2015), winter rainfall over continental China (Yuan et al. 2012), and storms in South-East Australia (Evans et al. 2012).

Most of the aforementioned RCM-based studies focus on relatively small target regions, which drastically reduces the degrees of freedom of their model (i.e., the possibility of the model to free oneself from lateral boundary forcing), and thus limits the influence of the model physics (Lucas-Picher et al. 2008; Leduc and Laprise 2009). Furthermore, these studies do not assess the path(s) by which the control of SW parameterization operates, and rarely test all the possible combinations of parameters, only way to properly quantify both the control of each type of parameterization and uncertainties within each type of parameterization. We propose to fill these gaps through analyzing multi-physics and multi-resolution tropicalchannel simulations done with the WRF model forced with prescribed sea surface temperatures (SSTs). This model is well suited for sensitivity studies since it incorporates a vast number of different physical parameterizations. Its tropical-channel configuration has been successfully used for studying tropical inertia-gravity waves (Evan et al. 2012), tropical tropopause (Evan et al. 2013), the Madden-Julian Oscillation (Ray et al. 2011; Ulate et al. 2015), and downscaling strategies (Hagos et al. 2013), but never for quantifying uncertainties in simulating tropical climate.

The purpose of this study is threefold: (i) assess the model skill in capturing key parameters of the energy budget and atmospheric water cycle and how this skill is sensitive to the model physics (SW, CU, PBL parameterizations), vertical and horizontal resolutions (VR and HR, respectively); (ii) quantify the control of SW parameterization on tropical climate and model skill relative to that of the other settings; (iii) investigate the physical mechanisms by which this control operates. Simulated SWnet_SFC, latent heat fluxes, and rainfall are 
analyzed at the annual timescale and evaluated against satellite-based observations.

Section 2 presents the tropical-channel simulations, the satellite-based observations, and how confidence is evaluated. Section 3 quantifies the control SW parameterization has on the model skill relative to that of the other settings, and identifies persistent model deficiencies across the parameters tested. Section 4 investigates how SW parameterization controls tropical climate simulation. Section 5 briefly discusses the respective influence of SW and CU parameterizations on tropical rainfall. Conclusions are provided in Section 6.

\section{Experimental setup, data, and confidence}

\subsection{Tropical-channel atmospheric simulations}

Four sets of tropical-channel simulations (Table 2) with prescribed SSTs are run using the Advanced Research WRF model (Skamarock et al. 2008) V3.3.1, with lateral boundaries placed at $46^{\circ}$ and the top of the atmosphere set at $50 \mathrm{hPa}$. All simulations are constrained by the 6-hourly 3/4 ${ }^{\circ}$ x 3/4 ${ }^{\circ}$ ERA-Interim reanalysis (ERA-I; Dee et al. 2011) and version 2 of the $1 / 4^{\circ} \times 1 / 4^{\circ}$ daily optimum interpolation SST analysis from NOAA (Reynolds et al. 2007), and are initialized on 00Z 1 January 1989.

Settings that are the same for the first three sets of simulations include Betts-MillerJanjic CU scheme (BMJ; Betts and Miller 1986, Janjic 1994), WSM6 MP scheme (Hong and Lim 2006), LW Rapid Radiative Transfer Model (RRTM; Mlawer et al. 1997), MoninObukhov surface layer, and the unified Noah LSM with surface characteristics from the MODIS 20-category land-cover classification (Chen and Dudhia 2001).

Set \#1 (Table 2) consists of 16 10-year long simulations (1989 - 1998 period) performed to (i) identify persistent biases whatever the settings tested, (ii) quantifying the control exerted by SW parameterization on the annual mean climatology of tropical climate, and (iii) testing the sensitivity of the results to different model settings. The 16 simulations correspond to all possible combinations between $2 \mathrm{SW}$ schemes, 2 PBL schemes, 2 VR and 2 HR refinements.

The two SW schemes selected are the Dudhia (Dudhia 1989) and Goddard (Chou and Suarez 1999) schemes. They are widely used for both weather forecasts and climate simulations, and perform best among extensive sensitivity tests achieved during the early stage of this work (not shown). The Dudhia scheme is a simple broadband downward 
166 integration that accounts for water vapor and cloud absorption, cloud albedo, and clear-air 167 scattering. The percentage of solar irradiance scattered in a model layer is directly 168 proportional to the layer-integrated density of the dry air and a bulk scattering coefficient. The 169 latter summarizes all scattering and absorption (aerosol and Rayleigh scattering, stratospheric 170 ozone and aerosol absorption) processes not explicitly included in the scheme, and its default 171 value $\left(10^{-5} \mathrm{~m}^{-2} \mathrm{~kg}^{-1}\right)$ is derived from atmospheric conditions observed during the First 172 International Satellite Land Surface Climatology Project Field Experiment (Zamora et al. 173 2005). The Goddard scheme accounts for the rapidly varying shortwave flux with 174 wavenumber by integrating solar flux into 11 spectral bands spanning from 0.175 to $10 \mu \mathrm{m}$, 175 and extinction by water vapor, ozone, oxygen, carbon dioxide, aerosols, Rayleigh scattering, 176 and clouds. Layer reflections and transmissions are computed using the $\delta$-Eddington 177 approximation (Joseph et al. 1976). Its accuracy is expected to be within a few W. $\mathrm{m}^{-2}$ whereas 178 the atmospheric heating rate between $0.01 \mathrm{hPa}$ and the surface is accurate to within $5 \%$ 179 relative to line-by-line calculations (Chou and Suarez 1999). The comparison of the simple 180 Dudhia scheme with a more classical SW scheme such as the Goddard allows physical understanding on the role of SW absorption over various regions.

The remaining settings, varying between the 16 simulations, include the non-local 183 Yonsei University (YSU; Hong et al. 2006) and turbulent kinetic energy Mellor-Yamada184 Nakanishi-Niino (MYNN; Mellor and Yamada 1982, Janjic 2002, Nakanishi and Niino 2004) 185 PBL schemes, 45 and 60 layers (L45 and L60 hereafter) VR, and 3/4 ${ }^{\circ}$ and $1 / 4^{\circ} \mathrm{HR}$. The L45 186 is the standard WRF configuration, and the L60 configuration has 3 times more levels below 187 $800 \mathrm{hPa}$.

To assess the robust effect of each model setting, two 8-member ensembles per model setting are selected from Set \#1. For instance, the two SW ensembles differ only from the SW scheme used and their 8 members are combinations between the 2 PBL schemes, the 2 VR and the 2 HR refinements tested. The control of SW parameterization is given by the spread within each of the two SW ensembles (i.e., inter-member spread) relative to the spread within 193 each of the two PBL, VR, and HR ensembles. A strong control of SW parameterization 194 corresponds to weaker inter-member spread within the two SW ensembles than within the two 195 PBL, VR, and HR ensembles, i.e. when the control is reproducible under different SW 196 schemes. On the other hand, the difference between the two SW ensemble means measures 197 the sensitivity to the way SW radiations are parameterized. The same methodology is applied 198 to the other settings. 
Sets \#2 to \#4 consist of 1-yr long simulations run for the year 1989 (Table 2). Set \#2 is 200 the same as Set \#1 but with 3/4 ${ }^{\circ} \mathrm{HR}$ and L60 VR. It helps understanding model biases by archiving additional diagnostics (see Table 2). Set \#3 is used for understanding the processes explaining differences between the two SW schemes, with an emphasis on their main differences: explicit $\mathrm{O}_{3}$ absorption in the Goddard scheme and the scattering coefficient in the Dudhia scheme. This is achieved by running and analyzing one Goddard simulation set without $\mathrm{O}_{3}$ absorption, and 11 Dudhia simulations with the scattering coefficient varying from $2 * 10^{-5} \mathrm{~m}^{-2} \mathrm{~kg}^{-1}$ to 0 every $0.2 * 10^{-5} \mathrm{~m}^{-2} \mathrm{~kg}^{-1}$. All simulations from Set \#3 use the YSU PBL scheme, L60 VR, and 3/4 $\mathrm{HR}$, a good compromise between model skill and computer resources. Set \#4 aims at discussing the relative weight CU and SW parameterizations have on tropical rainfall simulation. It is similar to the $83 / 4^{\circ} \mathrm{HR}$ simulations from Set \#1 but with the Kain-Fritsch (KF; Kain 2004) mass-flux instead of the BMJ adjustment-type CU scheme.

\subsection{Observations}

The model skill in simulating SWnet_SFC, latent heat fluxes, and rainfall is assessed against the annual mean climatology of different satellite-based datasets.

The annual climatology of SWnet_SFC is derived from the Cloud and Earth's Radiant 217 Energy System (CERES) Energy Balanced and Filled (EBAF edition 2.8) data over the 2000 - 2013 period. Commonly used for model output evaluation (e.g., Hourdin et al. 2013), the CERES-EBAF data include monthly mean radiation fluxes at the surface and the top of the atmosphere under full- and clear-sky conditions at a $1^{\circ}$ spatial resolution. They are produced by deriving the energy balance from AQUA, TERRA and geostationary satellites, and adjusting it to that inferred by Loeb et al. (2012) from the measured warming of the oceans. A complete description of the data is available in the CERES website

224 (http://ceres.larc.nasa.gov).

The Objectively Analysed air-sea Heat Fluxes version 3 dataset (OAFlux; Yu et al. $2008)$ is used for the annual climatology (1989 - 1998) of latent heat fluxes over ocean. These estimates result from a state-of-the-art flux parameterization applied to an optimal blending of surface meteorological parameters from satellite estimations, numerical weather predictions, and in situ measurements. They are available at the monthly timescale on a $1^{\circ} \mathrm{x} 1^{\circ}$ grid from 1998 onwards. 2007; Huffman and Bolvin 2013) is used for rainfall and its annual mean climatology is 
233 computed for the 1998 - 2007 period. This product provides 3-hourly estimates at a spatial 234 resolution of $1 / 4^{\circ}$ from 1998 to present.

235 Different thermo-dynamic parameters are also analyzed to understand model 236 deficiencies. We choose the ERA-I reanalysis, which is used to constrain all tropical-channel 237 simulations. ERA-I incorporates many improvements in model physics and analysis 238 methodology compared to the previous reanalyses. Included are a new 4D-var assimilation 239 scheme, higher horizontal resolution, a better formulation of background error constraint, 240 additional cloud parameters and humidity analysis, and more data quality control and bias 241 correction.

\subsection{Confidence}

All simulations from Set \#1 spin up within a few weeks in terms of energy budget and atmospheric water cycle, except latent heat fluxes over land points that require one year to spin up due to the low-frequency soil moisture adjustment. These simulations also slightly drift towards a more intense hydrological cycle over the 1989 - 1998 period, which reduces the amount of incident SW radiations at the surface through increase in water vapor absorption and stratiform cloud reflection. To ensure the robustness of our results to model spin-up and drift, we analyzed the model skill in simulating annual mean SWnet_SFC, latent heat fluxes and rainfall for each year over the 1989 - 1998 period compared to the observed annual mean climatology. Both the model skill and sensitivity to the settings are similar over the years, motivating to present only results for the annual mean climatology in section 3 .

We also verified that our results do not differ when (i) moving the temporal windows used for computing the observed annual climatology, and (ii) using different observational datasets (SWnet_SFC from the International Satellite Cloud Climatology Project: http://isccp.giss.nasa.gov/projects/flux.html; latent heat fluxes from the TropFlux data: Praveen Kumar et al. 2012; rainfall from version 2.2 of the Global Precipitation Climatology Project: http://www.esrl.noaa.gov/psd/data/gridded/data.gpcp.html). Model biases are only weakly sensitive to the period and datasets used. In other words, model errors are much larger than uncertainties related to observations.

The spatio-temporal scales analyzed in this study range from annual means at the grid point scale to daily means integrated either temporally (over the year) or spatially (over all/sea/land points within the tropical-channel domain), or both. These scales drastically reduce noise associated with model internal variability (Crétat et al. 2011), which would not 
267 be the case for high-frequency variability at the grid point scale. These caveats taken together

268 with the strong year-to-year reproducibility of our results clearly indicate that the model 269 internal variability is weak for the scales analyzed in our SST-forced simulations.

\section{Model evaluation: common strengths and weaknesses}

The model performance in representing the net SW radiation budget at the surface (Figure 1), latent heat fluxes (Figure 3) and rainfall (Figure 5) is summarized by using boxand-whisker plots of linear correlation coefficients between observed and simulated spatial distributions and the model root mean square errors.

\subsection{Net SW radiation budget at the surface}

Figure 1a shows the annual mean climatology of SWnet_SFC under full-sky conditions for the CERES-EBAF data. Maxima $\left(>250 \mathrm{~W} \cdot \mathrm{m}^{-2}\right)$ are found in the tropics over oceanic regions where cloud cover is weak. SWnet_SFC decreases both poleward due to the earth rotundity and equatorward due to the presence of deep convective clouds within the intertropical convergence zone (ITCZ). Large land/sea and meridian contrasts are also apparent due to larger albedo values over land and the presence of stratocumulus clouds over upwelling regions (e.g., Chile-Peru coast) and the south and east of China (Woods 2012), respectively. The two SW ensemble means struggle in capturing the observed spatial structure (Figs. 1b-c).

Figure 1d shows the spatial correlation ( $r$ ) in the annual mean climatology of SWnet_SFC between the 16 simulations from Set \#1 and the CERES-EBAF data. The spatial distribution depicted by the two SW ensemble means weakly differs one another, and the inter-member spread is high, pinpointing that SW parameterization does not drive the spatial distribution of SWnet_SFC.

For comparison, the remaining box-and-whisker plots show the inter-member spread within the two PBL, VR, and HR ensembles. The spatial distribution of SWnet_SFC is both more controlled by and sensitive to $\mathrm{PBL}$ parameterization and $\mathrm{HR}$ than to SW parameterization and VR. The mapping of differences between the two PBL or the two HR ensemble means points out low-level marine cloud regions, especially along and off the Chile-Peru coast (not shown). Moreover, the wide stretching of most box-and-whiskers in Fig. 1d suggests that the model skill in capturing the spatial distribution of SWnet_SFC 
301 depends more likely on combined effects of several parameters than on one particular 302 parameter. In this regard and for the metric analyzed in Fig. 1b, simulations combining either 303 the Dudhia or Goddard SW scheme with the YSU PBL scheme with L60 VR and 1/4 ${ }^{\circ}$ HR 304 largely outperform the others (not shown).

305 Figure 1e is the same as Fig. 1d but for the model root mean square errors (RMSE). The 306 spread within each SW ensemble is excessively weak compared to that found in the remaining 307 ensembles, reflecting a strong control of SW parameterization on the magnitude of 308 SWnet_SFC. Furthermore, great differences are found between the two SW ensemble means, 309 while the remaining ensemble means are almost the same. This traduces strong sensitivity of 310 SWnet_SFC magnitude to the SW scheme used, with RMSE value of $\sim 15$ W.m ${ }^{-2}$ and $\sim 27$ 311 W.m ${ }^{-2}$ for the Dudhia and Goddard SW ensemble means, respectively. The origins of these 312 differences are examined in more depth in section 4.

313 Despite magnitude differences, the two SW ensemble means display similar errors 314 spatially (Figs. 2a-b). First, they overestimate SWnet_SFC over convective areas (e.g., ITCZ, 315 South Pacific Convergence Zone, monsoon regions) due to underestimated cloud radiative 316 effects (Figs. 2c-d). This bias is shared by the 16 simulations (not shown) and is related to the absence of convective clouds in the BMJ CU scheme, which produces rainfall by adjusting 318 vertical profiles of moisture and temperature to observed profiles. The non-convective clouds 319 (resolved by the microphysics scheme) are therefore the only one existing in the model and 320 interacting with the SW and LW schemes. CMIP3 and CMIP5 GCMs display similar biases 321 (see, e.g., Fig. 5 in Li et al. 2013), because most of them struggle in representing cloud322 radiation interactions (Li et al. 2014). Second, SWnet_SFC is overestimated (underestimated) 323 along (off) the coastal upwelling regions (Fig. 2), especially in the Chile-Peru region. This 324 dipole indicates a westward shift in the location of simulated low-level marine clouds, a bias 325 sharply reduced when moving from $3 / 4^{\circ}$ to $1 / 4^{\circ} \mathrm{HR}$ whatever the $\mathrm{SW}$ scheme used (not 326 shown).

\subsection{Latent heat fluxes}

Figure 3a shows the annual mean climatology of latent heat fluxes for the OAFlux data.

331 The main sources of latent heat fluxes are located over western boundaries currents (>200

332 W.m ${ }^{-2}$ ), tropical and subtropical oceans (up to $120-160 \mathrm{~W} \cdot \mathrm{m}^{-2}$ in the Indian/Pacific and 333 Atlantic).

334 The spatial distribution and magnitude of latent heat fluxes over sea points are largely 
controlled by SW parameterization, while the remaining model settings have no impact (Figs

336 3b-c). The model skill significantly depends on the SW scheme used with Goddard SW simulations being more in line with the OAFlux data. Latent heat flux biases remain,

338 however, large whatever the SW scheme, with RMSE of 43 (32) W.m ${ }^{-2}$ for the Dudhia 339 (Goddard) SW ensemble mean. Spatially, the SW ensemble means systematically 340 overestimate latent heat fluxes over oceans (Figs. 4a-b). In the northern hemisphere, biases 341 increase westward in the Atlantic and Pacific Oceans and are the largest in the China Sea and 342 northern Indian Ocean. In the southern hemisphere, the main positive biases are located 343 equatorward of the Tropic of Capricorn in the three oceans.

344 These overestimations do not result from too intense surface winds simulated by the model since their speeds are underestimated (Figs. 4c-d), but they are consistent with biases in $3462 \mathrm{~m}$ specific humidity (Figs. 4e-f), with $\mathrm{r} \sim-0.78$ and -0.6 between the two parameters for the 347 Dudhia and Goddard SW ensemble means, respectively. This indicates that positive biases in 348 latent heat fluxes over the oceans at least partly result from overestimated moisture gradients 349 between the surface and the lower atmosphere.

\subsection{Rainfall}

Figure 5a shows the annual mean climatology of rainfall for the TRMM data. Largest rainfall amounts occur in convergence zones of each oceanic basin and over western boundary currents (Kuroshio and Gulf Stream).

The 16 simulations from Set \#1 accurately capture the observed spatial distribution (Fig. $5 b: r>0.75$ ), and the inter-simulation spread is relatively weak (greatest $r$ value $\sim 0.85$ ). This support the idea that the settings tested in this study do not significantly drive the large-scale distribution of rainfall, the latter being more influenced by prescribed SSTs and CU parameterization as expected from the literature (see section 5). Similar results are found for biases (Figs. 5c), with RMSE ranging between 1.4 and 2 mm.day ${ }^{-1}$.

The results are much more contrasted when disentangling sea and land points (Figs. 5d-

363 g). First, model errors and inter-member spread are larger over land than sea points, an 364 expected result since the WRF model is forced by observed SSTs over seas while coupled with a LSM elsewhere. One important exception is weaker inter-member spread in the spatial distribution of rainfall simulated over land by the two HR ensembles, due to the strong control exerted by the orography (Fig. 5f). Second, the differences in rainfall biases found between the two SW (or HR) ensembles are clearly reversed over sea and land points. Both the Dudhia 
$369 \mathrm{SW}$ and $1 / 4^{\circ} \mathrm{HR}$ ensembles produce more (less) biases over sea (land) points than the

370 Goddard SW and 3/4 ${ }^{\circ}$ HR ensembles (Figs. 5e and g). The weak differences found between 371 the two SW / HR ensembles at the tropical-channel scale (Fig. 5c) hide thus large spatial 372 differences (Figs. 6a-b), with, e.g., large (moderate) wet biases over the tropical Indian Ocean 373 and China Sea, and dry (wet) biases over South America and Southeast Asia in the Dudhia 374 (Goddard) SW ensemble mean.

375 Despite regional differences, some large-scale errors are obviously shared by the two $376 \mathrm{SW}$ ensemble means. These errors include prominently a 2-3 mm.day ${ }^{-1}$ dry bias over the 377 Indian subcontinent and a 4-6 mm.day ${ }^{-1}$ wet bias over the Pacific ITCZ. The wet bias is not reminiscent of the classical double-ITCZ problem (Lin 2007; Oueslati and Bellon 2015) and is partly related to too strong moisture convergence in the two SW ensemble means (Figs. 6cd). Biases of similar magnitude are also found within a zonal band stretching from the Bay of Bengal to far off the Philippine east coast in line with underestimated summer monsoon flux (Samson et al. 2015) and consistent with latent heat flux and moisture convergence biases (Figs. 4a-b and 6c-d, respectively).

In summary, the model skill significantly varies according to the model settings, but common weaknesses persist whatever the model physics and resolution, especially the underestimation of cloud radiative effects over convective regions, and huge biases in latent heat fluxes. SW parameterization significantly influences tropical climate simulation, with large repercussions on the radiative budget itself, but also the energy budget and water cycle. The weight of SW parameterization relative to that of CU parameterization will be assessed in

\section{Sensitivity to SW schemes} section 5 .

Section 4 diagnostics the differences between the two SW schemes, and addresses their

4.1 Quantifying the differences induced by the two SW schemes

Figure 7 shows annual mean climatology differences between the Dudhia and Goddard 
403 Dudhia SW ensemble mean (Fig. 7a). The largest differences occur in the western Pacific and 404 Atlantic Oceans, the South Pacific Convergence Zone (30-40 W.m ${ }^{-2}$ in both regions), and in the tropical Indian Ocean (30-36 W.m $\left.{ }^{-2}\right)$. Small differences $\left(0-14 \mathrm{~W} \cdot \mathrm{m}^{-2}\right)$ are located inland where convection is deep during summer or year-round (i.e., tropical Africa, maritime continent, southeast Asia, and Amazon basin), and in low-level marine cloud regions where the Goddard SW scheme produces more low-level clouds (explicitly resolved by the model) than the Dudhia (see discussion of the Figure 9c), hence less downward SW at the surface.

There is significant spatial anti-correlation between differences in SWnet_SFC (Fig. 7a) and in rainfall (Fig. 7b), with $\mathrm{r} \sim-0.54$. This indicates that differences in SWnet_SFC decrease where rainfall amounts are larger in the Goddard than the Dudhia SW ensemble mean, and reversely. This involves the effects of stratiform clouds (e.g., anvil clouds resolved by the microphysics) that develop above convective regions (see Figs. 10c-d), consistent with strong positive relationship between convective and stratiform rainfall in our simulations (not shown). The Goddard SW simulates more rainfall over land than the Dudhia SW ensemble, whereas it is the opposite over maritime convective regions, except in the western equatorial Pacific. Over land, differences in rainfall are mainly related to differences in latent heat fluxes. The Goddard produces warmer surface temperatures than the Dudhia SW scheme in response to larger SWnet_SFC. This favors more evaporation, increases the moist static energy below the cloud base and, finally, produces more rainfall. Over sea, where SSTs are prescribed, enhanced rainfall over maritime convective regions in the Dudhia SW ensemble is predominantly associated with higher latent heat fluxes and moisture convergence as demonstrated by the striking similarities between the different patterns (Figs. 7b-d).

Since SW parameterization has direct effects on the thermal structure of the atmosphere, we focus on the thermal stability of the atmosphere to understand the mechanisms by which SW parameterization controls tropical climate simulation. Figures 8a-b show the zonal mean in the annual mean climatology of potential temperature $(\theta)$ averaged over sea points for the Goddard SW ensemble mean from Set \#1 and the differences between the two SW ensemble means, respectively. The focus is given to sea points to avoid mixing SST-prescribed and coupled land-atmosphere regions for which differences between the two SW schemes are reversed (Fig. 7). Note, however, that zonal averaging applied to all grid points within the tropical-channel domain leads to similar results since sea points represent $75 \%$ of the total. As expected, the strong vertical gradient of $\theta$ observed at mid-latitudes turns weak in the tropics (Fig. 8a). However, the Goddard SW ensemble mean simulates a more stable tropical atmosphere with warmer $\theta$ as pressure decreases (Fig. 8b). This is in accordance with weaker 
updraft (Figs. 8c-d) and lower high-level stratiform clouds (Figs. 8e-f) simulated on either side of the equator by the Goddard simulations. Finally, differences in rainfall (Fig. 7b), vertical velocity (Fig. 8d), and stratiform clouds (Fig. 8f) traduce a thinner marine ITCZ in the meridional direction when using the Goddard SW scheme.

To understand land/sea contrasts shown in Fig. 7, Figure 9 shows differences in the vertical profile of $\theta$ between the two SW ensemble means over both sea and land points. The effects SW parameterization has on atmospheric stability depend on whether surface is coupled to atmosphere or not. Over sea points where SSTs do not respond to changes in radiations, the atmosphere is more stable in the Goddard than the Dudhia SW ensemble mean, with differences being almost null at the surface because $\theta$ is constrained to adjust to prescribed SSTs and increasing with height. Over land points, the use of a LSM allows surface temperatures to respond to changes in radiations, as measured by large spread in the Dudhia - Goddard differences at the surface. These differences are almost uniform between the near surface and $\sim 500 \mathrm{hPa}$ (in the 1.2-1.4 $\mathrm{K}$ range), indicating a shift towards a warmer state in the Goddard SW ensemble mean. This induces weaker surface pressure and higher moist static energy simulated by the Goddard than the Dudhia SW scheme (not shown), hence conditions more favorable for convection to develop.

\subsection{Understanding the differences induced by the two SW schemes}

To quantify which components of the model physics explain the differences in the vertical profile of $\theta$ seen in Figure 9, we extracted the physics tendencies of $\theta$ in the Goddard simulation with $\mathrm{O}_{3}$ absorption and the Dudhia simulation with the default scattering coefficient from Set \#2. These two simulations are defined as control simulations in the following. The tendencies are computed online to avoid aliasing effect, and are extracted using a cumulative averaging methodology.

Figures 10a-e show the zonal mean in $\theta$ tendencies for the Goddard control simulation 464 over sea points. As expected, 4 out of the 5 terms warm the atmosphere. SW radiations warm the whole atmosphere through gas absorption (e.g., water vapor, $\mathrm{CO}_{2}, \mathrm{O}_{3}$ ) (Fig. 10a), $\mathrm{CU}$ and MP processes warm the low- and mid-troposphere by releasing latent heat fluxes (Figs. 10c-

$467 \mathrm{~d}$ ), and PBL turbulence warms the low-troposphere (below $950 \mathrm{hPa}$ ) by vertical diffusion 468 (Fig. 10e). Most of these warming effects are counter-balanced by the strong cooling effect of 469 LW radiations in the whole atmosphere (Fig. 10b) and, to a lesser extent, of low-tropospheric 470 cloud and rainfall evaporation induced by MP processes (Fig. 10d). Horizontal diffusion has 
no significant effect (not shown).

Differences in $\theta$ tendencies between the two control simulations (Figs. 10f-j) are important for the 5 terms, demonstrating that SW schemes affect climate simulation through interactions with all components of the model physics. We illustrate this point by focusing on differences in deep and shallow convections induced by SW schemes. In the tropics, negative differences in $\theta$ tendencies due to CU and MP found between 950 and $300 \mathrm{hPa}$ (Figs. 10h-i) suggest that deep maritime convection is less intense and thinner in the meridional direction in the Goddard than the Dudhia control simulation, consistent with Figs. $7 \mathrm{~b}$ and 8d. On the other hand, positive differences at $15^{\circ} \mathrm{S}$ and $15^{\circ} \mathrm{N}$ below $850 \mathrm{hPa}$ (Figs. 10h-i) suggest more intense shallow convection over marine low-level cloud regions in the Goddard than the Dudhia control simulation, consistent with Fig. 8f.

Furthermore, it turns out that differences in the vertical profile of $\theta$ (Fig. 9) can only be explained by those induced by SW radiations. The contribution of the latter to $\theta$ tendencies is uniform and larger in almost the whole troposphere in the Goddard than the Dudhia control simulation (Fig. 10f). The exception is around 300-200 $\mathrm{hPa}$ because of the large part of downward SW radiations absorbed by $\mathrm{O}_{3}$ above these levels by the Goddard SW scheme. Differences in $\theta$ tendencies due to the remaining physical parameterizations are negative or compensate each other.

Two main candidates contribute in explaining differences induced by the two SW schemes: $\mathrm{O}_{3}$ absorption in the Goddard scheme and the Dudhia scattering coefficient. Figure 11 investigates how these parameters modify the vertical stability of the atmosphere by comparing zonal means of $\theta$ annual mean using simulations from Set \#3 (Table 2). Fig. 11a shows differences between the two control simulations. It is the same as Fig. 8b but for the year 1989 , and is shown as a baseline. Setting $\mathrm{O}_{3}$ concentration to 0 sharply modifies $\theta$ near the model top but does not modulate its vertical profile below (Fig. 11b). Associated differences in latent heat fluxes and rainfall are weak in magnitude and quite noisy spatially (not shown). This means that $\mathrm{O}_{3}$ absorption does not explain the large differences between the two control simulations and that modifying atmospheric temperatures above $300 \mathrm{hPa}$ does not significantly affect tropical climate in our simulations. Switching off the Dudhia scattering does not warm the model top due to the absence of explicit $\mathrm{O}_{3}$ absorption in the Dudhia scheme, but does stabilize the atmosphere below so that differences with the Goddard control simulation become insignificant (Fig. 11c). Similar results are obtained the way around, i.e., when comparing Dudhia simulations with and with no scattering (Fig. 11d). This indicates that the strength of the Dudhia scattering coefficient drives the magnitude of differences 
between the two SW schemes tested.

Figure 12 quantifies the sensitivity of the vertical profile in annual mean $\theta$ to the strength of the Dudhia scattering coefficient. Results are similar over both sea and land points (Figs. 12a-b). Differences remain large at $100 \mathrm{hPa}$ whatever the scattering value due once again to the absence of explicit $\mathrm{O}_{3}$ absorption in the Dudhia scheme. On the other hand, they sharply reduce below $100 \mathrm{hPa}$ as the scattering value decreases, until turning positive with the Dudhia scattering switched off. Decreasing the scattering coefficient acts thus in increasing atmospheric stability over sea points where SSTs are prescribed, and shifting the whole vertical profile of $\theta$ towards a warmer state over land points where surface temperatures respond to SW radiations. This enhances thermal contrast between land and sea, hence strengthens monsoon system and associated circulation.

Figure 13 quantifies to what extent the value of the Dudhia scattering coefficient 517 modulates the degree of agreement with the Goddard control simulation in the spatial 518 distribution and magnitude of SWnet_SFC, latent heat fluxes, and rainfall. Reducing the

519 Dudhia scattering coefficient results in both increased spatial agreement (Figs. 13a-c) and reduced magnitude differences (Figs. 13d-f) with the Goddard control simulation. According to the parameter and metric analyzed, the maximal consistency between the two SW schemes is found when the Dudhia scattering coefficient ranges between $\sim$ half its default value and 0 .

\section{Discussion}

A large body of literature identifies CU parameterization as a significant, if not the main, source of uncertainty for simulating tropical climate, while the impact of SW parameterization is often neglected. Here, we disentangle the relative weight CU and SW parameterizations have on tropical rainfall simulation by analyzing the $83 / 4^{\circ} \mathrm{HR}$ simulations from Set \#1 and from Set \#4 (Table 2). We do not disentangle stratiform rainfall resolved by

$532 \mathrm{MP}$ and convective rainfall resolved by $\mathrm{CU}$ for brevity and because impact studies require 533 total rainfall to constrain hydrological and agronomic models. Results found for the total 534 rainfall do not necessarily prevail when disentangling stratiform and convective rainfall, notably because the contribution of convective rainfall to total rainfall varies according to both the CU scheme used and rainfall intensities considered (not shown).

Figure 14 focuses on the control CU and SW parameterizations have on the spatial distribution and magnitude of annual mean rainfall. The box-and-whisker plots are the same 
539 as in Figs. 5d-g but for the spread within the 2 CU and 2 SW ensembles. Regarding the spatial 540 distribution of rainfall over sea points (Fig. 14a, first four plots), the control of CU and SW 541 parameterizations is roughly the same and does not radically differ from that exerted by the remaining settings tested in this study (Fig. 5d). This confirms that the spatial distribution of rainfall over SST-prescribed regions depends on combined effects of different model settings.

544 This conclusion does not stand for land points (Fig. 14a, last four plots) where CU 545 parameterization drives the spatial distribution of rainfall, while SW parameterization has no 546 impact. The control of CU parameterization appears to be as important as that exerted by HR 547 (Fig. 5f), with the KF largely outperforming the BMJ scheme. On the other hand, SW parameterization has the largest control on rainfall magnitude over both sea and land points (Fig. 14b) and biases are very sensitive to the SW scheme used, especially over land points where differences in rainfall biases reach $1 \mathrm{~mm}$.day ${ }^{-1}$ between the two SW ensemble means, against only $\sim 0.3 \mathrm{~mm}$.day ${ }^{-1}$ between the two CU ensemble means (Fig. 14b, last four plots). This result unambiguously demonstrates that annual rainfall amounts are much more (i)

553 driven by SW than CU parameterization in these tropical simulations, and (ii) sensitive to the 554 SW than the CU schemes tested.

We finally analyze the control of $\mathrm{CU}$ and SW parameterizations on daily rainfall distribution. We make use of a PDF-like approach consisting in weighting the probability of occurrence of each rainfall bin according to their contribution to annual rainfall amounts so that both the number of rainy events and their daily intensity are considered. For each simulation, we extracted events in the space-time matrix (space: sea/land points within the tropical-channel domain; time: the 365 days of the year 1989) for which daily rainfall amount ranges between 0 and $1 \mathrm{~mm} \cdot$ day $^{-1}$, and so on up to $100 \mathrm{~mm}^{-d a y}{ }^{-1}$, every $1 \mathrm{~mm}$.day ${ }^{-1}$. We then accumulate these amounts for each rainfall bin. The two CU and the two SW ensembles are then constructed, and the same methodology is applied to the TRMM data for each year of the 1998 - 2007 period. Figures 15a-b present the results over sea and land points for the two CU and the two SW ensemble means relative to the TRMM climatology. Figs. 15b-c show the associated control of CU and SW parameterizations, computed as the coefficient of variation

567 within each ensemble (i.e., inter-member standard deviation divided by the ensemble mean) 568 for each rainfall bin. Results are summarized as follows:

569 - Model biases are physics dependent mainly for light rainy events over sea points (Fig. 570 15a: $\sim 0-5 \mathrm{~mm} \cdot \mathrm{day}^{-1}$ range) with strong sensitivity to $\mathrm{CU}$ schemes, and for moderate rainy 571 events over land points (Fig. 15b: 20-40 mm.day ${ }^{-1}$ range) with strong sensitivity to both CU 572 and SW schemes; 
573 - The sign of differences between the two CU schemes varies according to rainfall bins 574 over both sea and land points, which is not the case between the two SW schemes. This 575 suggests that $\mathrm{CU}$ parameterization shapes the probability density function of rainfall, and that $576 \mathrm{SW}$ parameterization controls rainfall intensity whatever the range considered;

577 - The control of CU and SW parameterizations is large over sea points, while rather 578 weak over land points, consistent with Fig. 15b. Over sea points (Fig. 15c), the contribution of 579 light rainy events is mostly controlled by $\mathrm{CU}$ parameterization, indicating that the latter is critical for convection triggering under neutral atmospheric conditions. On the other hand, the contribution of moderate rainy events $\left(\sim 20-50 \mathrm{~mm}^{\left.-d_{a}{ }^{-1}\right)}\right.$ is further controlled by SW parameterization, suggesting that large-scale atmospheric profiles are important for this range of rainy events.

\section{Conclusion}

This study (i) highlights model deficiencies in representing the main components of the energy budget and water cycle in the tropics that are insensitive to major model settings, (ii) assesses the control SW parameterization has on tropical climate simulation relative to that of the remaining model settings tested, and (iii) helps understanding the mechanisms by the control of SW parameterization operates.

This is achieved by running 10-yr and 1-yr long tropical-channel simulations with prescribed SSTs using the WRF model driven by the ERA-I reanalysis. Simulations include sensitivity tests to the model physics (two schemes of SW, CU, and PBL parameterizations), resolution (L45 and $\mathrm{L} 60 \mathrm{VR}, 3 / 4^{\circ}$ and $1 / 4^{\circ} \mathrm{HR}$ ), and to the way SW radiations (explicitly or implicitly) interact with the atmosphere in the two SW schemes used. Analyses focus on the spatial distribution and magnitude of SWnet_SFC, latent heat fluxes, and rainfall at the annual timescale. The model skill is quantified relative to up-to-date observations (e.g., CERESEBAF, OAFlux, and TRMM).

Our tropical-channel simulations suffer from two main common deficiencies. First,

602 SWnet_SFC is systematically overestimated over regions where convection is deep (e.g., Fig.

603 2) due to the absence of feedback between convective clouds and SW radiations. Such 604 feedback has recently been incorporated into the WRF model V3.6 between the KF CU 605 scheme and the RRTMG (Rapid Radiative Transfer Model for global models) SW and LW 606 schemes (Alapaty et al. 2012). This feedback helps reducing downward SW radiations at the 
surface over the U.S., which moderates the surface forcing for convection and results in

608 reduced rainfall biases. Second, latent heat fluxes are largely overestimated over warm pool regions of the tropical ocean (Figs. 4a-b). One possible cause involves overestimated moisture gradient between the surface and the subsurface due to too dry conditions simulated in the

611 low-troposphere. Other possible reasons involve overestimated radiative imbalance between 612 surface and atmosphere arising from the first deficiency, hence more need of latent heat 613 fluxes to compensate the imbalance excess (Wild and Liepert 2010), too strong surface 614 atmosphere exchange coefficients and the absence of ocean - atmosphere coupling.

Among the model settings tested, SW parameterization has a paramount influence on tropical climate, which is in line with, e.g., Pohl et al. (2011). SW parameterization clearly drives the magnitude of SWnet_SFC (Fig. 1) and rainfall (Figs. 5, 14, and 15) and both the spatial distribution and magnitude of latent heat fluxes over sea points (Fig. 3) in our model configuration. This differs from findings by Di Luca et al. (2014) who state that latent heat fluxes in the Mediterranean Sea is weakly sensitive to SW parameterization. The reason of such disagreement involves differences in the experimental setup, with the use of strongly constrained simulations (nudging applied above the PBL) by Di Luca et al. (2014), acting in reducing the degree of freedom of their model. The impact of the remaining model settings is nonetheless non negligible. The spatial distribution of rainfall mainly depends on CU parameterization and HR over land. That of SWnet_SFC depends slightly more on PBL parameterization and HR, which modify the location and/or intensity of low-marine clouds. Note that including convective cloud - SW radiation feedbacks would probably increase the control of SW and CU parameterizations on the spatial distribution of SWnet_SFC.

Despite their large influence on tropical climate, SW radiations remain challenging to simulate and highly uncertain in climate models, as evidenced by large differences found between Dudhia and Goddard SW simulations used in their default mode (Fig. 7). The model skill depends on the metrics and parameters analyzed, so that none of the two SW schemes systematically outperforms the other (Figs. 1-7). The two SW schemes profoundly modify the vertical structure of the atmosphere according to the way they handle SW absorption/reflection/scattering throughout the troposphere and whether surface responds to SW forcing or not. The Goddard absorbs much more downward SW than the Dudhia scheme (Figs. 8-12). The reason is the scattering coefficient used in the Dudhia SW scheme for emulating aerosol and Rayleigh scattering, and stratospheric ozone and aerosol absorption

639 (Fig. 11). The surplus of SW absorption further stabilizes the troposphere over sea where 640 surface temperatures are prescribed (i.e., sea points), while results in a shift towards a warmer 
641 state over land where surface is coupled to atmosphere (i.e., land points). The consequences

642 are less (more) latent heat fluxes and rainfall simulated by the Goddard than the Dudhia SW

643 scheme over sea (land) points. Decreasing the Dudhia scattering coefficient allows sharp

644 increase in SW absorption, so that differences between the two SW schemes are cancelled out

645 or reversed when switching off the scattering coefficient in the Dudhia SW scheme (Figs. 12-

$64613)$.

647 This study demonstrates the usefulness of tropical-channel simulations to investigate 648 tropical climate dependency to the model physics and resolutions. It also highlights the need

649 for improving SW parameterization, which is not only the main driver of tropical climate but 650 also one of the most uncertain components of the model physics. Additional work is needed to 651 quantify to what extent the inclusion of convective cloud - SW radiation feedbacks improves 652 the model skill in simulating tropical climate, to understand the impact of the remaining 653 model settings tested in this study, and to test the robustness of our results in an air-sea 654 coupled framework with the Nemo - Oasis - WRF modeling system (Samson et al. 2014).

655

656

657 Acknowledgments

658

659 This work was funded by the European Commission's 7th Framework Programme, under 660 Grant Agreement number 282672, EMBRACE project, and by the project PULSATION 661 ANR-11-MONU-0010 of the French National Research Agency (ANR). WRF was provided 662 by the University Corporation for Atmospheric Research 663 (http://www2.mmm.ucar.edu/wrf/users/download/get_source.htm). Simulations are performed 664 on the Curie supercomputer, owned by GENCI and operated into the TGCC by CEA. We 665 acknowledge PRACE for awarding us access to the Curie supercomputer thought its 3rd, 5th 666 and 9th calls. We also thank the two anonymous reviewers for their helpful comments. 
Alapaty K, Herwehe JA, Otte TL, Nolte CG, Bullock OR, Mallard MS, Kain JS, Dudhia J (2012) Introducing subgrid-scale cloud feedbacks to radiation for regional meteorological and climate modeling. Geophys Res Lett 39, L24809, doi:10.1029/2012GL054031

Betts AK, Miller MJ (1986) A new convective adjustment scheme. Part II: single column tests using GATE wave, BOMEX, ATEX and arctic air-mass data sets. Q J R Meteorol Soc 112:693-709

Chen F, Dudhia J (2001) Coupling an advanced land-surface/hydrology model with the Penn State/NCAR MM5 modeling system. Part I: model description and implementation. Mon Weather Rev 129:569-585

Chou MD, Suarez MJ (1999) A solar radiation parameterization for atmospheric studies, Tech. Rep. NASA/TM-1999-104606 Vol. 15, Technical Report Series on Global Modeling and Data Assimilation NASA

Crétat J, Macron C, Pohl B, Richard Y (2011) Quantifying internal variability in a regional climate model: a case study for Southern Africa. Clim Dyn 37:1335-1356

Crétat J, Pohl B, Richard Y, Drobinski P (2012) Uncertainties in simulating regional climate 685 of Southern Africa: sensitivity to physical parameterizations using WRF. Clim Dyn 38:613-634

Dee DP et al. (2011) The ERA-Interim reanalysis: configuration and performance of the data assimilation system. Q J R Meteorol Soc 137:553-597

Di Luca A, Flaounas E, Drobinski P, Lebeaupin Brossier C (2014) The atmospheric component of the Mediterranean Sea water budget in a WRF multi-physics ensemble and observations. Clim Dyn 43:2349-2375

Dudhia, J. (1989), Numerical study of convection observed during the winter monsoon experiment using a mesoscale twodimensional model. J Atmos Sci 46:3077-3107

Evan S, Alexander MJ, Dudhia J (2012) Model study of intermediate-scale tropical inertiagravity waves and comparison to TWP-ICE campaign observations. J Atm Sci 69:591-610

Evan S, Rosenlof KH, Dudhia J, Hassler B, Davis SM (2013) The representation of the TTL in a tropical channel version of the WRF model. J Geophys Res Atm 118:2835-2848

Evans JP, Ekström M, Ji F (2012) Evaluating the performance of a WRF physics ensemble over South-East Australia. Clim Dyn 39:1241-1258

Flaounas E, Bastin S, Janicot S (2011) Regional climate modelling of the 2006 West African monsoon: sensitivity to convection and planetary boundary layer parameterisation using 
WRF. Clim Dyn 36:1083-1105

Hagos S, Leung R, Rauscher SA, Ringler T (2013) Error Characteristics of Two Grid Refinement Approaches in Aquaplanet Simulations: MPAS-A and WRF. Mon Weather Rev 141:3022-3036

Hong SY, Lim JOJ (2006) The WRF Single-Moment 6-class microphysics scheme (WSM6), J Korean Meteor Soc 42:129-151

Hong SY, Noh Y, Dudhia J (2006) A new vertical diffusion package with an explicit treatment of entrainment processes. Mon Weather Rev 134:2318-2341

Hourdin F, Grandpeix JY, Rio C, Bony S, Jam A, Cheruy F, Rochetin N, Fairhead L, Idelkadi A, Musat I, Dufresne JL, Lahellec A, Lefebvre MP, Roehrig R (2013) LMDZ5B: the atmospheric component of the IPSL climate model with revisited parameterizations for clouds and convection. Clim Dyn 40:2193-2222

Huffman GJ, Bolvin DT (2013) TRMM and other data precipitation data set documentation. ftp://rsd.gsfc.nasa.gov/pub/trmmdocs/3B42_3B43_doc.pdf

Huffman GJ, Adler RF, Bolvin DT, Gu G, Nelkin EJ, Bowman KP, Hong Y, Stocker EF, Wolff DB (2007) The TRMM multisatellite precipitation analysis: quasi-global, multiyear, combined sensor precipitation estimates at fine scale. J Hydrom 8:38-55

Janjic ZI (1994) The step-mountain eta coordinate model: further developments of the convection, viscous sublayer, and turbulence closure schemes. Mon Weather Rev 122:927-945

Janjic ZI (2002) Nonsingular implementation of the Mellor-Yamada level 2.5 scheme in the NCEP meso model. NCEP Office Note N 437, 61 pp

Joseph JH, Wiscombe WJ, Weinman JA (1976) The delta-Eddington approximation for radiative flux transfer. J Atmos Sci 33:2452-2459

Kain JS (2004) The Kain-Fritsch convective parameterization: an update. J Appl Meteor 43:170-181

Kala J, Andrys J, Lyons TJ, Foster IJ, Evans BJ (2015) Sensitivity of WRF to driving data and physics options on a seasonal time-scale for the southwest of Western Australia. Clim Dyn 44:633-659

Kothe S, Ahrens B (2010) On the radiation budget in regional climate simulations for West Africa. J Geophys Res 115, doi:10.1029/2010JD014331

Leduc M, Laprise R (2009) Regional climate model sensitivity to domain size. Clim Dyn $32: 833-854$

Li JLF, Waliser DE, Stephens G, Lee S, L'Ecuyer T, Kato S, Loeb N, Ma HY (2013) 
Characterizing and understanding radiation budget biases in CMIP3/CMIP5 GCMs, contemporary GCM, and reanalysis. J Geophys Res Atmos 118, 8166-8184, doi:10.1002/jgrd.50378

Li JLF, Lee WL, Waliser DE, Neelin JD, Stachnik JP, Lee T (2014) Cloud-precipitationradiation-dynamics interaction in global climate models: A snow and radiation interaction sensitivity experiment. J Geophys Res Atmos 119, doi:10.1002/2013JD021038

Li R, Jin J, Wang SY, Gillies RR (2015) Significant impacts of radiation physics in the Weather Research and Forecasting model on the precipitation and dynamics of the West African monsoon. Clim Dyn 44:1583-1594

Lim YK, Schubert SD, Reale O, Lee MI, Molod AM, Suarez MJ (2015) Sensitivity of tropical cyclones to parameterized convection in the NASA GEOS-5 model. J Clim 28:551-573

Lin JL (2007) The double-ITCZ problem in IPCC AR4 coupled GCMs: ocean-atmosphere feedback analysis. J Clim 18:4497-4525

Loeb NG, Lyman JM, Johnson GC, Allan RP, Doelling DR, Wong T, Soden BJ, Stephens GL (2012) Observed changes in top-of-the-atmosphere radiation and upper-ocean heating consistent within uncertainty. Nature Geosciences, doi:10.1038/NGE

Lucas-Picher P, Caya, D, Biner S, Laprise R (2008) Quantification of the lateral boundary forcing of a regional climate model using an aging tracer. Mon Weather Rev 136:49804996

Mellor GL, Yamada T (1982) Development of a turbulence closure model for geophysical fluid problems. Rev Geophys Space Phys 20:851-875

Mlawer E, Taubman S, Brown P, Iacono M, Clough S (1997) Radiative transfer for inhomogeneous atmosphere: RRTM, a validated correlated-k model for the long-wave. J Geophys Res 102:16663-16682

Morcrette JJ, Barker HW, Cole JS, Iacono MJ, Pincus R (2008) Impact of a new radiation package, McRad, in the ECMWF Integrated Forecasting System. Mon Weather Rev $163: 4773-4798$

Nakanishi M, Niino H (2004) An improved Mellor-Yamada level-3 model with condensation physics: Its design and verification. Bound Layer Meteor 112:1-31

Oueslati B, Bellon G (2015) The double ITCZ bias in CMIP5 models: interaction between SST, large-scale circulation and precipitation. Clim Dyn 44:585-607 Rocha RP, Mourão C, Jacob D (2014) The surface radiation budget over South America in a set of regional climate models from the CLARIS-LPB project. Clim Dyn 43:1221-1239 
Pohl B, Crétat J, Camberlin P (2011) Testing WRF capability in simulating the atmospheric water cycle over equatorial East Africa. Clim Dyn 37:1357-1379

Praveen Kumar B, Vialard J, Lengaigne M, Murty VSN, McPhaden MJ (2012) TropFlux: airsea fluxes for the global tropical oceans - description and evaluation against observations. Clim Dyn 38:1521-1543

Raktham C, Bruyère C, Kreasuwun J, Done J, Thongbai C, Promnopas W (2015) Simulation sensitivities of the major weather regimes of the Southeast Asia region Clim Dyn 44:14031417

Ray P, Zhang C, Moncrieff MW, Dudhia J, Caron JM, Leung LR, Bruyère C (2011) Role of the atmospheric mean state on the initiation of the Madden-Julian oscillation in a tropical channel model. Clim Dyn 36:161-184

Reynolds RW, Smith TM, Liu C, Chelton DB, Casey KS, Schlax MG (2007) Daily highresolution-blended analyses for sea surface temperature. J Clim 20:5473-5496

Samson G, Masson S, Lengaigne M, Keerthi MG, Vialard J, Pous S, Madec G, Jourdain NC, Jullien S, Menkes C, Marchesiello P (2014) The NOW regional coupled model: Application to the tropical Indian Ocean climate and tropical cyclone activity. $\mathbf{J} \mathrm{Adv}$ Model Earth Syst 6:700-722

Samson G, et al. (2015) Role of land surface albedo on the Asian summer monsoon biases in a coupled ocean-atmosphere tropical-channel model. Submitted to Clim Dyn

Skamarock W, Klemp JB, Dudhia J, Gill D, Barker D, Duda M, Huang X, Wang W, Powers J (2008) A description of the Advanced Research WRF Version 3. NCAR Technical Note NCAR/TN-475+STR, doi:10.5065/D68S4MVH.

\section{http://www2.mmm.ucar.edu/wrf/users/docs/arw_v3.pdf}

Ulate M, Zhang C, Dudhia J (2015) Role of water vapor and convection-circulation decoupling in MJO simulations by a tropical channel model. J Adv Model Earth Syst, doi: 10.1002/2014MS000393

Wehner MF, Reed KA, Li F, Prabhat, Bacmeister J, Chen CT, Paciorek C, Gleckler PJ, Sperber KR, Collins WD, Gettelman A, Jablonowski C (2014) The effect of horizontal resolution on simulation quality in the Community Atmospheric Model, CAM5.1. J Adv Model Earth Syst 6:980-997

Wild M, Liepert B (2010) The Earth radiation balance as driver of the global hydrological cycle. Environ Res Lett 5, doi:10.1088/1748-9326/5/2/025003

Wild M, Folini D, Schär C, Loeb N, Dutton EG, König-Langlo G (2013) The global energy balance from a surface perspective. Clim Dyn 40:3107-3134 
804 Wang H, Su W (2013) Evaluating and understanding top of the atmosphere cloud radiative 805 effects in Intergovernmental Panel on Climate Change (IPCC) Fifth Assessment Report 806 (AR5) Coupled Model Intercomparison Project Phase 5 (CMIP5) models using satellite 807 observations. J Geophys Res Atmo 118:683-699

808 Wood R (2012) Stratocumulus clouds. Mon Wea Rev 140:2373-2423

$809 \mathrm{Xu}$ J, Small EE (2002) Simulating summertime rainfall variability in the North American 810 monsoon region: The influence of convection and radiation parameterizations. J Geophys $811 \quad$ Res 107, doi:10.1029/2001JD002047

812 Yu L, Jin X, Weller RA (2008) Multidecade global flux datasets from the Objectively 813 Analyzed Air-sea Fluxes (OAFlux) project: latent and sensible heat fluxes, ocean 814 evaporation, and related surface meteorological variables. Woods Hole Oceanographic 815 Institution, OAFlux Project Technical Report. OA-2008-01, 64pp. Woods Hole. $816 \quad$ Massachusetts

817 Yuan X, Liang XZ, Wood E (2012) WRF ensemble downscaling seasonal forecasts of China 818 winter precipitation during 1982-2008. Clim Dyn 39:2041-2058

819 Zamora RJ, Dutton EG, Trainer M, McKeen SA, Wilczak JM, Hou YT (2005) The accuracy 820 of solar irradiance calculations used in mesoscale numerical weather prediction. Mon Wea $821 \quad$ Rev 133:783-792 


\section{Table Captions}

823

824 Table 1: $\quad$ List of the main acronyms used.

825

826 Table 2: $\quad$ Summary of the 4 sets of simulations used with grey shadings showing the $827 \quad$ settings tested.

828 


\section{$830 \quad$ Figure Captions}

832 Figure 1: (a) Annual mean climatology in the net SW radiation budget at the surface 833 (SWnet_SFC; W.m-2) under full-sky conditions for the CERES-EBAF data interpolated onto 834 the grid of $3 / 4^{\circ}$ simulations. (b-c) Same as (a) but for the Dudhia and Goddard SW ensemble 835 means from Set \#1. (d) Box-and-whisker plots for the Bravais-Pearson linear correlation (r) in 836 the annual mean climatology of tropical-channel SWnet_SFC between the 16 simulations 837 from Set \#1 and the CERES-EBAF data. The two first box-and-whisker plots contain the 8 838 members of the Dudhia and Goddard SW ensembles, respectively. The 3 next pairs of box839 and-whisker plots are the same, but for the two PBL, VR, and HR ensembles, respectively 840 (see Table 1 for acronyms). Note that $1 / 4^{\circ} \mathrm{HR}$ simulations are interpolated onto the grid of $8413 / 4^{\circ} \mathrm{HR}$ simulations. The boxes have lines at the lower quartile, median and upper quartile 842 values. The whiskers are lines extending from each end of the boxes and show the extent of 843 the range of the data within 1.5 by interquartile range from the upper and lower quartiles. 844 Stars are $\mathrm{r}$ values for ensemble means and plus signs are outliers. (e) Same as (d) but for the model root mean square errors (RMSE).

847 Figure 2: (a-b) Biases in the annual mean climatology of SWnet_SFC (W.m ${ }^{-2}$ ) under 848 full-sky conditions for the Dudhia and Goddard SW ensemble means from Set \#1, 849 respectively, with respect to the CERES-EBAF data. (c-d) Same as (a-b) but under cloudysky conditions for the two 1-yr long SW ensembles from Set \#2.

852 Figure 3: (a) Annual mean climatology in latent heat fluxes $\left(\mathrm{W} \cdot \mathrm{m}^{-2}\right)$ for the OAFlux data 853 interpolated onto the grid of $3 / 4^{\circ}$ HR simulations. (b-c) Same as Figs. 1d-e but for latent heat 854 fluxes over sea points within the tropical-channel domain.

856 Figure 4: (a-b) Biases in the annual mean climatology of latent heat fluxes (W. $\mathrm{m}^{-2}$ ) for 857 the Dudhia and Goddard SW ensemble means from Set \#1, respectively. (c-d and e-f) Same 858 as (a-b) but for $10 \mathrm{~m}$ wind speed $\left(\mathrm{m}^{-\mathrm{s}^{-1}}\right)$ and $2 \mathrm{~m}$ specific humidity $\left(\mathrm{g} \cdot \mathrm{kg}^{-1}\right)$ biases against the ERA-I and OAFlux data, respectively.

861 Figure 5: (a) Annual mean climatology in rainfall $\left(\mathrm{mm}^{-d a y}{ }^{-1}\right.$ ) for the TRMM data 862 interpolated onto the grid of $3 / 4^{\circ} \mathrm{HR}$ simulations. (b-c) Same as Figs. 1d-e but for rainfall. (d- 
863 e and f-g) Same as (b-c) but for sea and land points within the tropical-channel domain, 864 respectively.

866 Figure 6: (a-b) Biases in the annual mean climatology of rainfall (mm.day ${ }^{-1}$ ) for the 867 Dudhia and Goddard SW ensemble means from Set \#1, respectively. (c-d) Same as (a-b) but 868 for 1000 to $700 \mathrm{hPa}$ vertically-averaged moisture fluxes (vectors) and moisture flux 869 convergence (shadings) biases against the ERA-I data.

871 Figure 7: Differences in the annual mean climatology of (a) SWnet_SFC, (b) rainfall, (c) 872 latent heat fluxes, and (d) 1000 to $700 \mathrm{hPa}$ vertically-averaged moisture fluxes (vectors) and moisture flux convergence (shadings) between the Goddard and Dudhia SW ensemble means from Set \#1.

(a) Vertical-meridional cross-section in the annual mean climatology of potential temperature $(\mathrm{K})$ averaged over sea points for the Goddard SW ensemble mean from Set \#1. (b) Differences between the Goddard and Dudhia SW ensemble means (contours every $0.2 \mathrm{~K}$ ). (c-d and e-f) Same as (a-b) but for vertical velocity $\left(\mathrm{m} \cdot \mathrm{s}^{-1}\right)$ and cloud fraction from the microphysics (ratio) with contours every $0.0005 \mathrm{~m} . \mathrm{s}^{-1}$ and 0.01 , respectively. In (c) and (d) positive velocity is upward.

Figure 9: Differences in the vertical profile of the annual mean climatology of potential temperature averaged over sea (purple) and land (green) points between the Goddard and Dudhia SW ensembles from Set \#1. Solid lines show the differences between the 8 members of the Goddard and Dudhia SW ensembles. Bold lines show the differences between the two ensemble means.

Figure 10: (a-e) Vertical-meridional cross-section of potential temperature tendencies due to the parameterization of SW, LW, CU, MP, and PBL for the Goddard control simulation

891 from Set \#3, respectively (see Table 1 for acronyms). Tendencies are accumulated at the daily timescale then averaged over the year 1989. (f-j) Same as (a-e) but for the differences between the Goddard and Dudhia control simulations from Set \#3.

895 Figure 11: Vertical-meridional cross-section in the differences of potential temperature 896 (K) between (a) the two control simulations from Set \#3, (b) the Goddard control simulation 
and that with no $\mathrm{O}_{3}$ absorption, (c) the Goddard control simulation and the Dudhia simulation

898 with no scattering, and (d) between the Dudhia simulation with no scattering and the Dudhia control simulation.

900

901 Figure 12: Differences in the vertical profile of annual mean potential temperature 902 averaged over (a) sea and (b) land points between the Goddard control simulation and the 11

903 Dudhia simulations with the scattering coefficient varying from $2 \times 10^{-5}$ to 0 every $0.2 \times 10^{-5}$.

904 The black line is zero difference.

905

906 Figure 13: Spatial correlation in the annual mean (a) SWnet_SFC, (b) latent heat fluxes, 907 and (c) rainfall between the Goddard control simulation and 10 Dudhia simulations with the 908 scattering coefficient varying from $2 \times 10^{-5}$ to 0 every $0.2 \times 10^{-5}$. (d-f) Same as (a-c) but area909 averaged differences. Black circles correspond to all grid points within the tropical-channel

910 domain. Green and purple dots denote land and sea points within the tropical-channel domain, 911 respectively.

912

$913 \quad$ Figure 14: Same as Figs. 5d-g but for the two CU and SW ensembles.

914

915 Figure 15: Biases of the two CU and SW ensemble means in rainfall amounts 916 accumulated over (a) sea and (b) land points within the tropical-channel domain for the year 9171989 according to daily rainfall intensity. Ranges of rainfall intensity vary from 0 to 100 $918 \mathrm{~mm}^{-d a{ }^{-1}}$, every $1 \mathrm{~mm} \cdot \mathrm{day}^{-1}$. Biases are computed against the TRMM climatology computed 919 for the 1998 - 2007 period. (c-d) Same as (a-b) but for the coefficient of variation of each 920 ensemble (\%) computed as the ratio between the inter-member standard deviation and the 921 ensemble mean. 


\begin{tabular}{|c|c|c|}
\hline 923 & Models and data & \\
\hline 924 & CERES-EBAF & Cloud and Earth's Radiant Energy System Energy Balanced and Filled (edition 2.8) \\
\hline 925 & CMIP5 & Climate Model Intercomparison Project Phase 5 \\
\hline 926 & ERA-I & ERA-Interim reanalysis \\
\hline 927 & GCM & Global Climate Model \\
\hline 928 & OAFlux & Objectively Analysed air-sea Heat Fluxes (version 3) \\
\hline 929 & $\mathbf{R C M}$ & Regional Climate Model \\
\hline 930 & TRMM & NASA 3B42-V7 Tropical Rainfall Measuring Mission \\
\hline 9331 & WRF & Weather Research and Forecasting \\
\hline 933 & Model settings & \\
\hline 935 & $\mathbf{C U}$ & convection \\
\hline 936 & HR & horizontal resolution \\
\hline 937 & LSM & Land Surface Model \\
\hline 938 & $\mathbf{L W}$ & longwave \\
\hline 939 & MP & microphysics \\
\hline 940 & PBL & planetary boundary layer \\
\hline 941 & SW & shortwave \\
\hline 942 & VR & vertical resolution \\
\hline 943 & $\mathbf{L 4 5}$ & 45 layers in the vertical \\
\hline 944 & L60 & 60 layers in the vertical \\
\hline 946 & Other & \\
\hline 948 & ITCZ & Inter-Tropical Convergence Zone \\
\hline 949 & RMSE & root mean square errors \\
\hline 950 & SST & sea surface temperature \\
\hline 951 & SWnet_SFC & net $S W$ radiation budget at the surface \\
\hline 853 & $\theta$ & potential temperature \\
\hline
\end{tabular}

955 Table 1: List of the main acronyms used. 


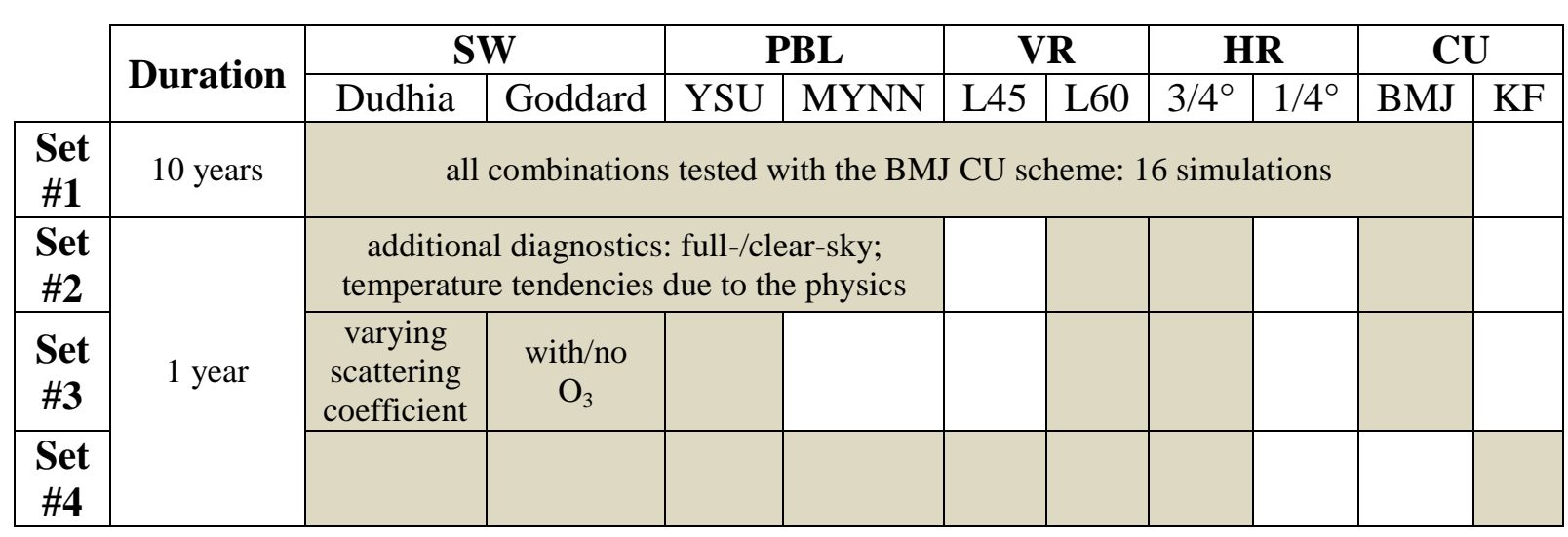

957 Table 2: Summary of the 4 sets of simulations used with grey shadings showing the settings 958 tested. 

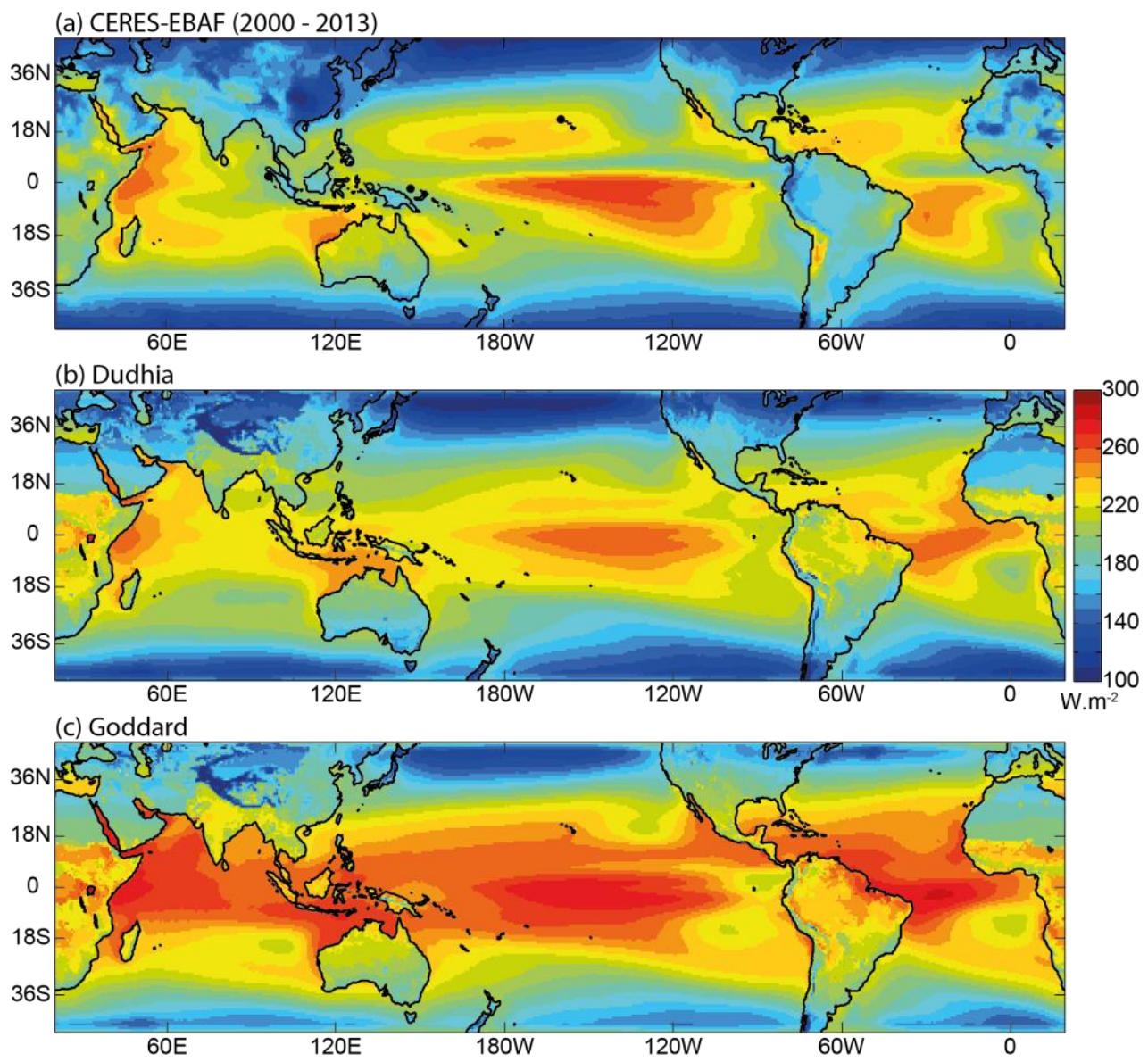

(d) Spatial distribution

(e) Biases
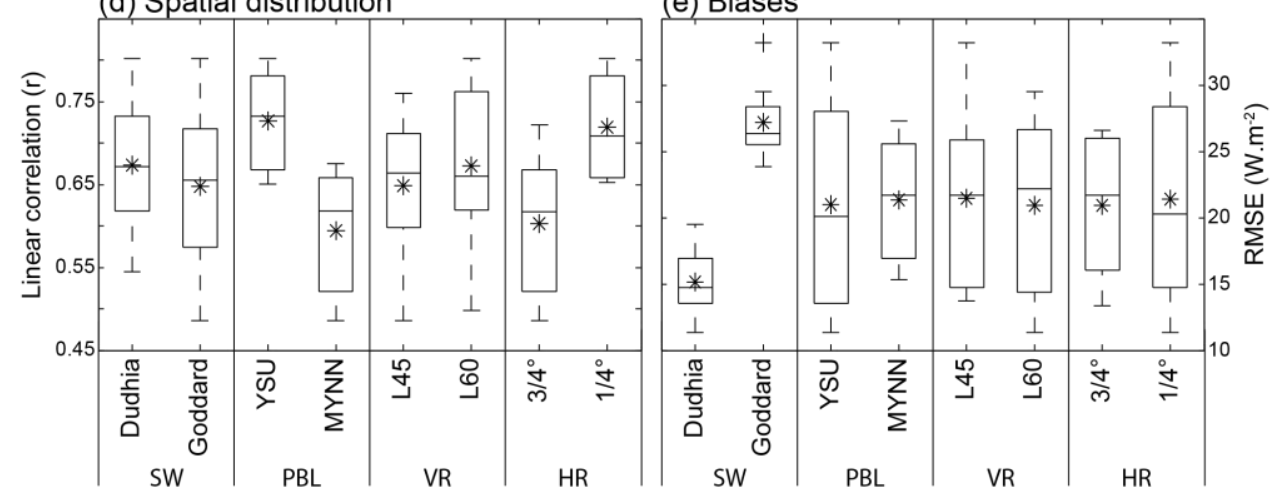

Figure 1: (a) Annual mean climatology in the net SW radiation budget at the surface (SWnet_SFC; W. $\mathrm{m}^{-2}$ ) under full-sky conditions for the CERES-EBAF data interpolated onto the grid of $3 / 4^{\circ}$ simulations. (b-c) Same as (a) but for the Dudhia and Goddard SW ensemble means from Set \#1. (d) Box-and-whisker plots for the Bravais-Pearson linear correlation (r) in the annual mean climatology of tropical-channel SWnet_SFC between the 16 simulations from Set \#1 and the CERES-EBAF data. The two first box-and-whisker plots contain the 8 members of the Dudhia and Goddard SW ensembles, respectively. The 3 next pairs of boxand-whisker plots are the same, but for the two PBL, VR, and HR ensembles, respectively (see Table 1 for acronyms). Note that $1 / 4^{\circ} \mathrm{HR}$ simulations are interpolated onto the grid of $3 / 4^{\circ}$ HR simulations. The boxes have lines at the lower quartile, median and upper quartile values. The whiskers are lines extending from each end of the boxes and show the extent of the range of the data within 1.5 by interquartile range from the upper and lower quartiles. Stars are $r$ values for ensemble means and plus signs are outliers. (e) Same as (d) but for the model root mean square errors (RMSE). 
(a) Dudhia -- Full-sky

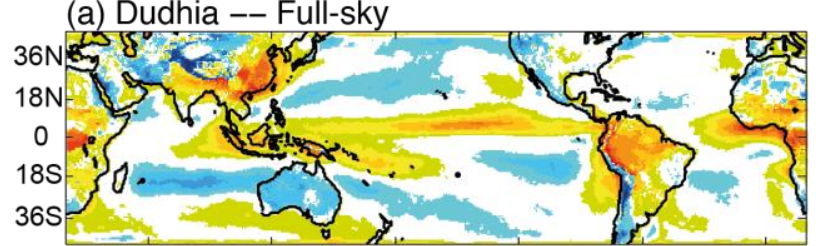

(c) Dudhia -- Cloudy-sky
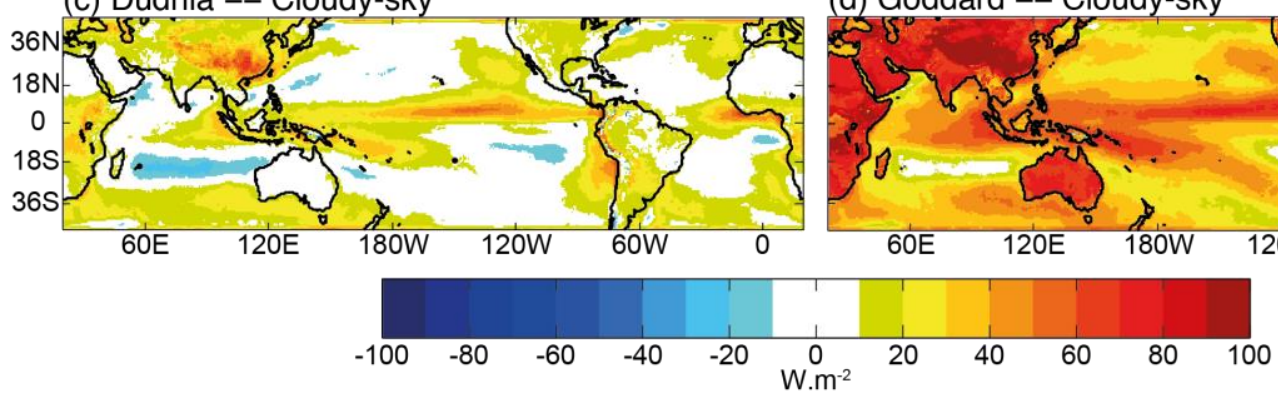

(d) Goddard -- Cloudy-sky (b) Goddard -- Full-sky
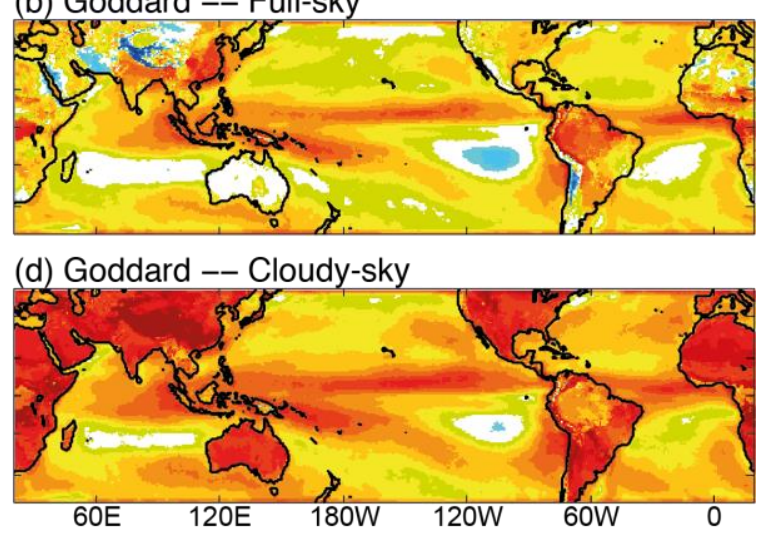

Figure 2: (a-b) Biases in the annual mean climatology of SWnet_SFC (W.m $\mathrm{m}^{-2}$ ) under full-sky conditions for the Dudhia and Goddard SW ensemble means from Set \#1, respectively, with respect to the CERES-EBAF data. (c-d) Same as (a-b) but under cloudy- 
(a) OAFlux (1989 - 1998)
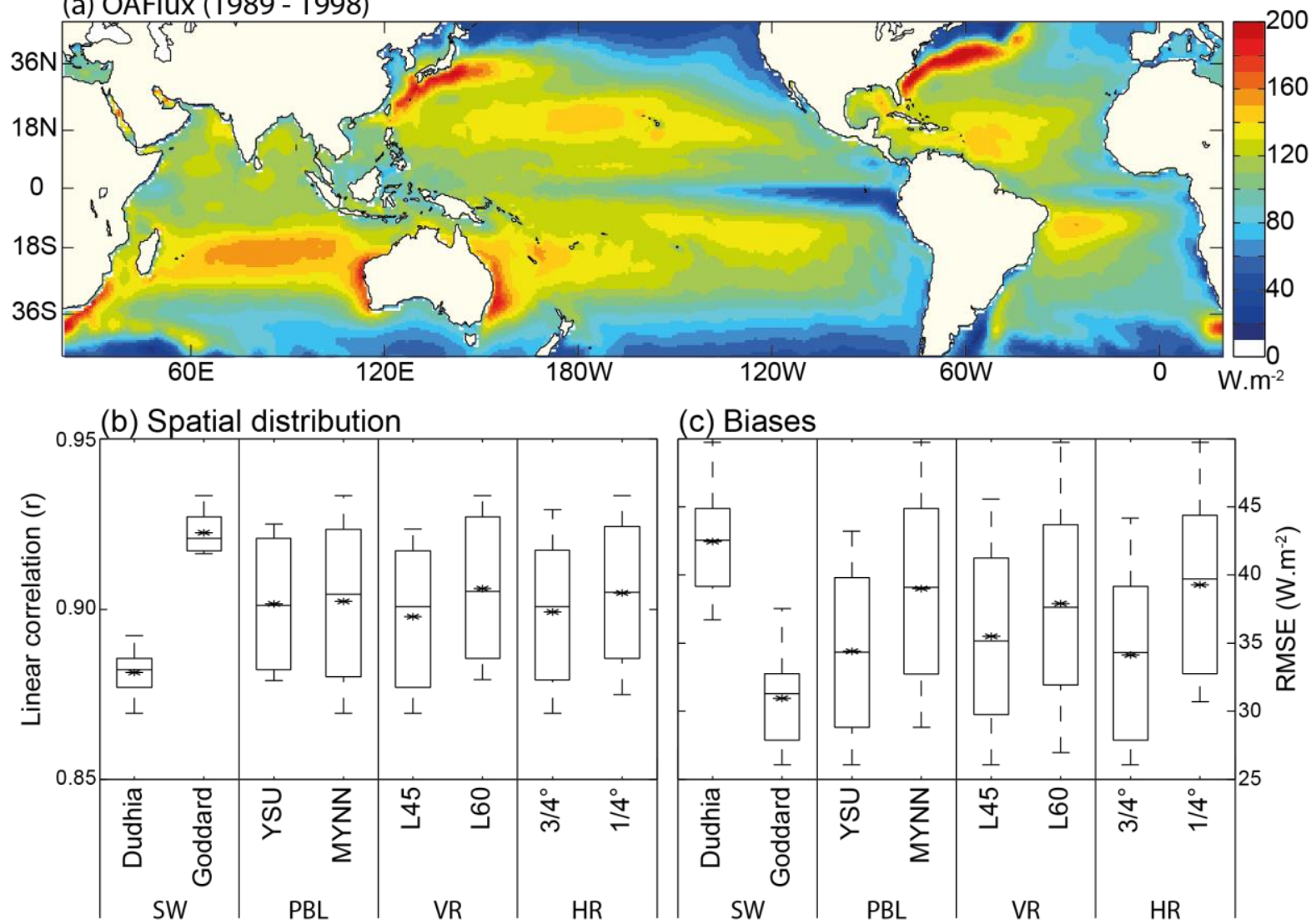

(c) Biases

Figure 3: (a) Annual mean climatology in latent heat fluxes $\left(W \cdot m^{-2}\right)$ for the OAFlux data 984 interpolated onto the grid of $3 / 4^{\circ} \mathrm{HR}$ simulations. (b-c) Same as Figs. 1d-e but for latent heat 985 fluxes over sea points within the tropical-channel domain. 
(a) Dudhia -- Latent heat fluxes
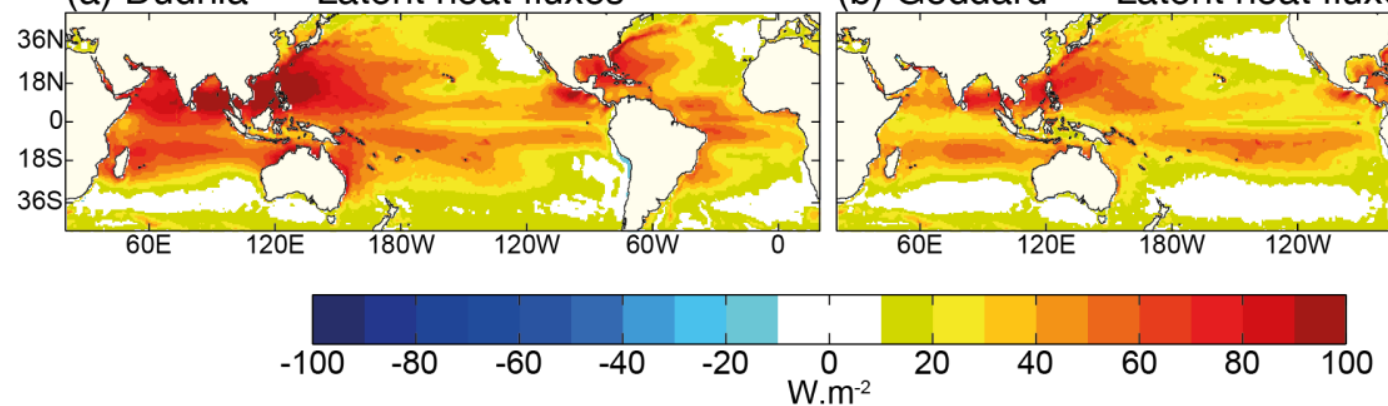

(b) Goddard -- Latent heat fluxes

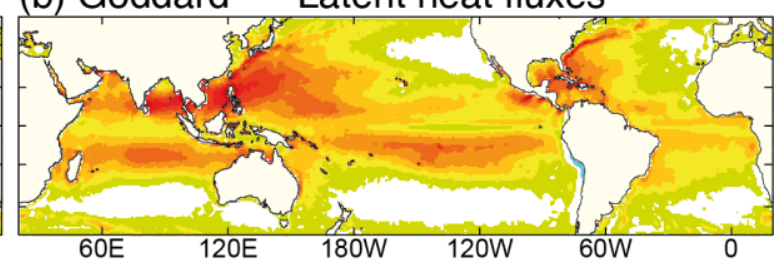

(c) Dudhia -- $10 \mathrm{~m}$ wind speed

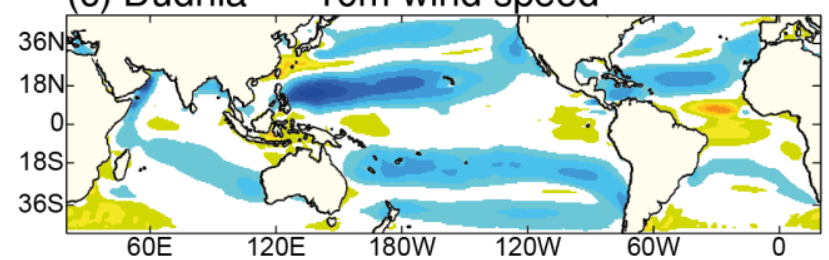

(d) Goddard -- 10m wind speed
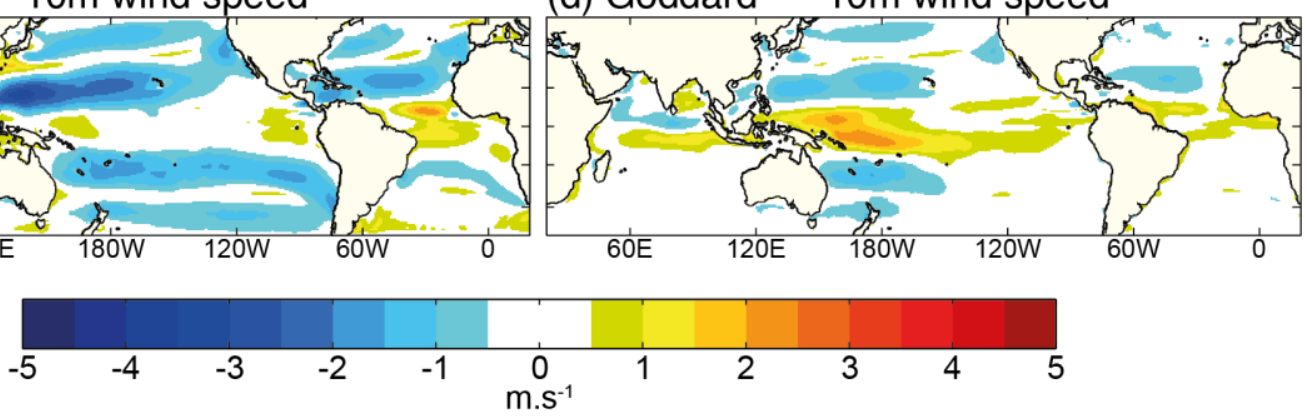

(f) Goddard -- $2 \mathrm{~m}$ specific humidity
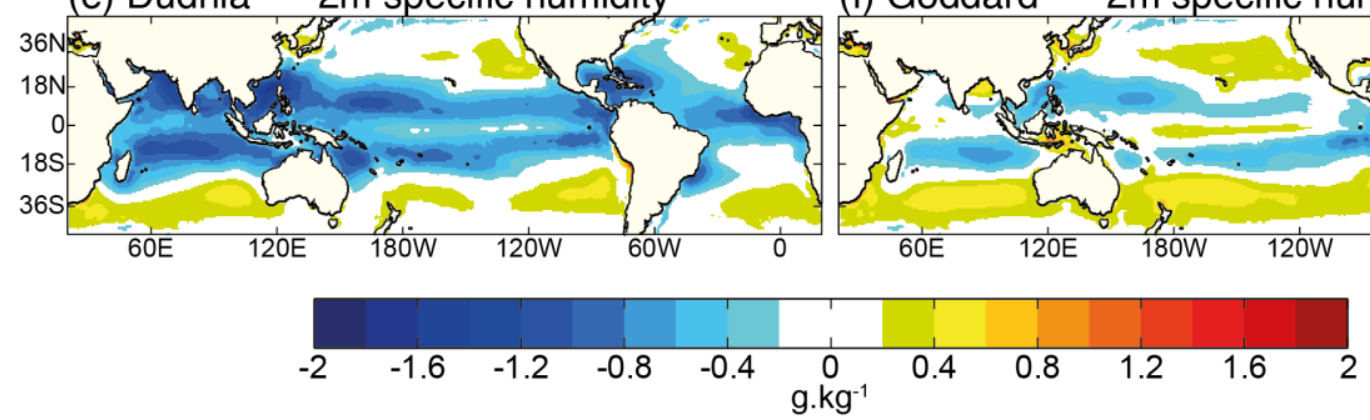

Figure 4: (a-b) Biases in the annual mean climatology of latent heat fluxes $\left(\mathrm{W} . \mathrm{m}^{-2}\right)$ for the Dudhia and Goddard SW ensemble means from Set \#1, respectively. (c-d and e-f) Same as $(\mathrm{a}-\mathrm{b})$ but for $10 \mathrm{~m}$ wind speed $\left(\mathrm{m}^{-1} \mathrm{~s}^{-1}\right)$ and $2 \mathrm{~m}$ specific humidity $\left(\mathrm{g} \cdot \mathrm{kg}^{-1}\right)$ biases against the

991 ERA-I and OAFlux data, respectively. 
(a) TRMM 3B42-V7 (1998 - 2007)

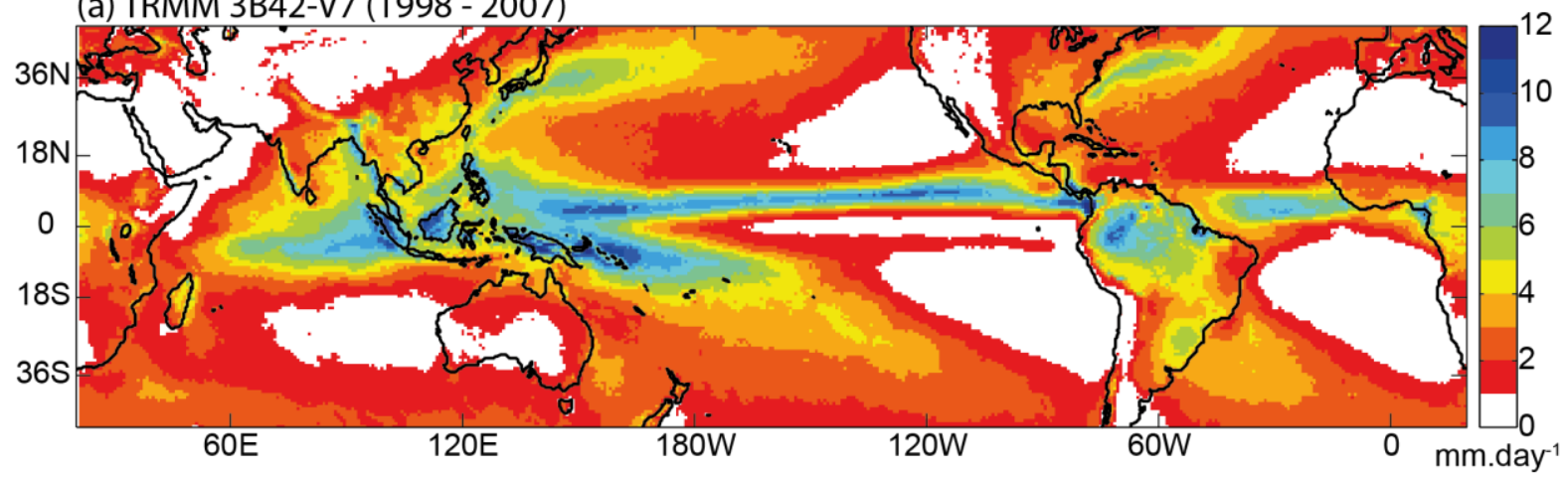

(b) Spatial distribution -- All grid points

(c) Biases -- All grid points
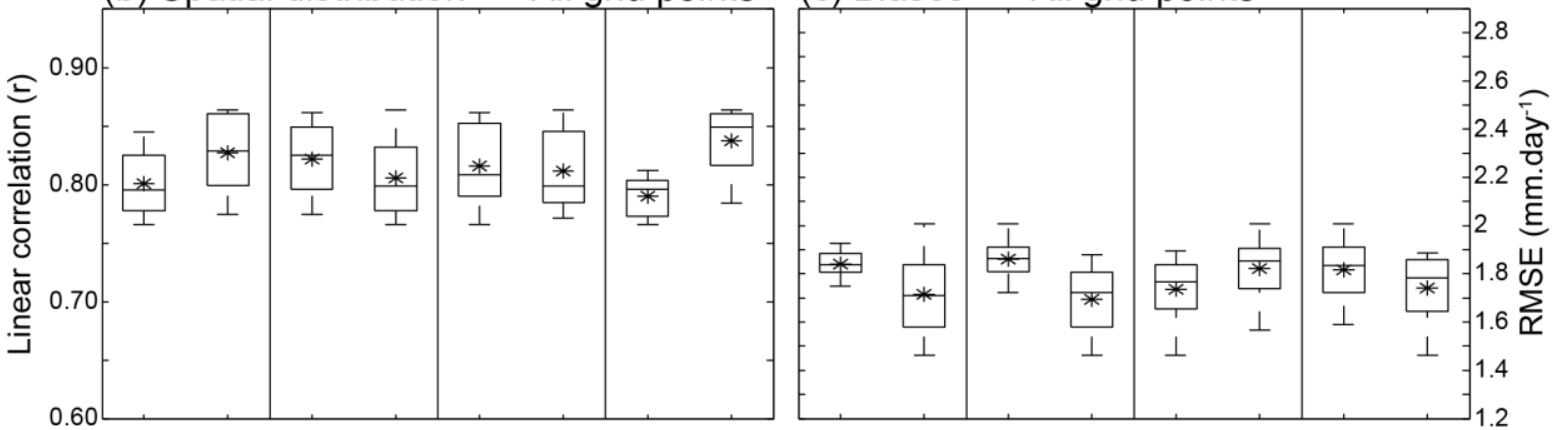

(d) Spatial distribution -- Sea points

(e) Biases -- Sea points
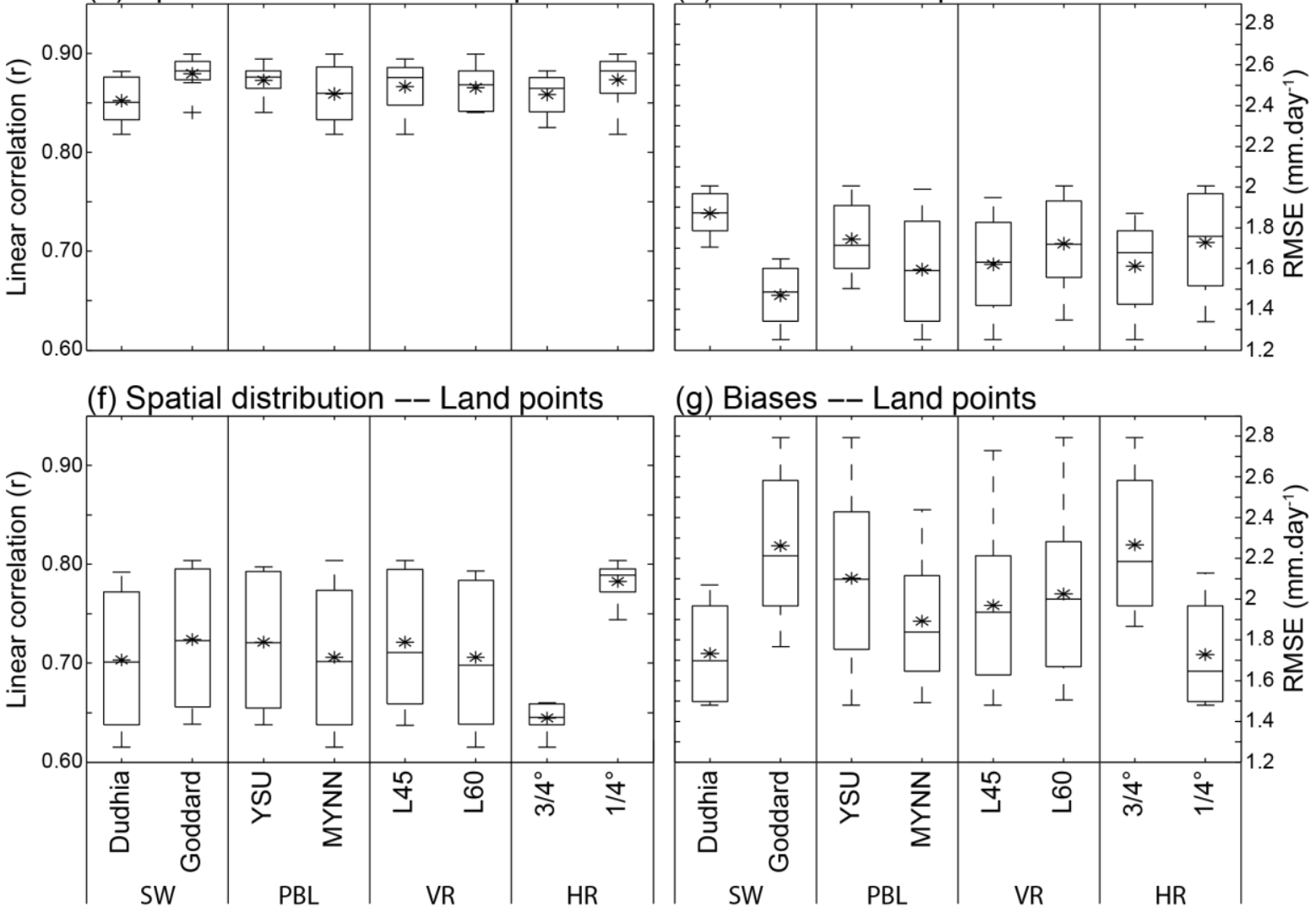

(g) Biases -- Land points

Figure 5: (a) Annual mean climatology in rainfall $\left(\mathrm{mm} \cdot \mathrm{day}^{-1}\right)$ for the TRMM data 995 interpolated onto the grid of 3/4 ${ }^{\circ}$ HR simulations. (b-c) Same as Figs. 1d-e but for rainfall. (d996 e and f-g) Same as (b-c) but for sea and land points within the tropical-channel domain, 997 respectively. 
(a) Dudhia -- Rainfall biases

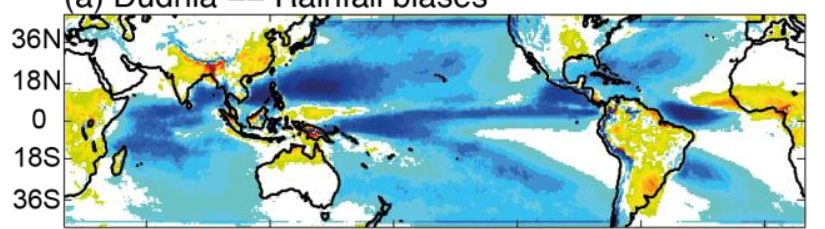

(b) Goddard -- Rainfall biases

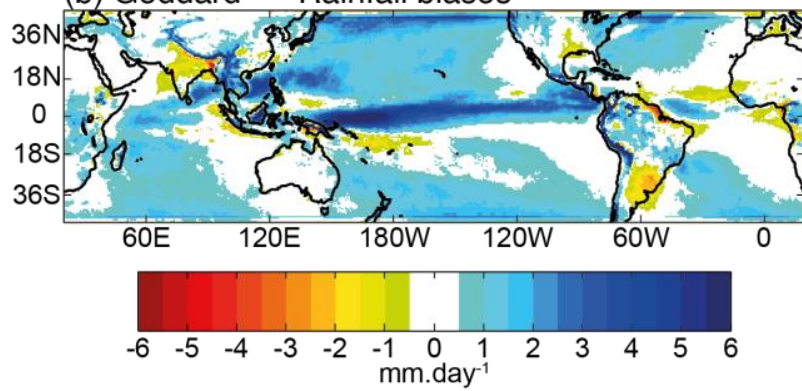

(c) Dudhia -- Moisture flux / convergence biases

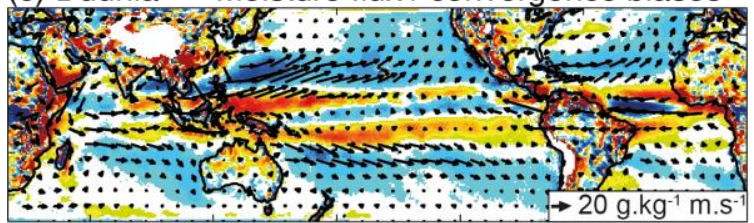

(d) Goddard -- Moisture flux / convergence biases

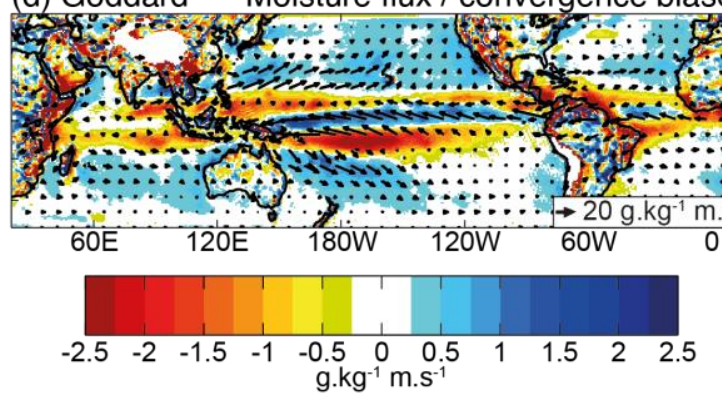

Figure 6: (a-b) Biases in the annual mean climatology of rainfall (mm.day ${ }^{-1}$ ) for the 1001 Dudhia and Goddard SW ensemble means from Set \#1, respectively. (c-d) Same as (a-b) but 1002 for 1000 to $700 \mathrm{hPa}$ vertically-averaged moisture fluxes (vectors) and moisture flux 1003 convergence (shadings) biases against the ERA-I data. 
(a) Goddard - Dudhia -- SWnet_SFC

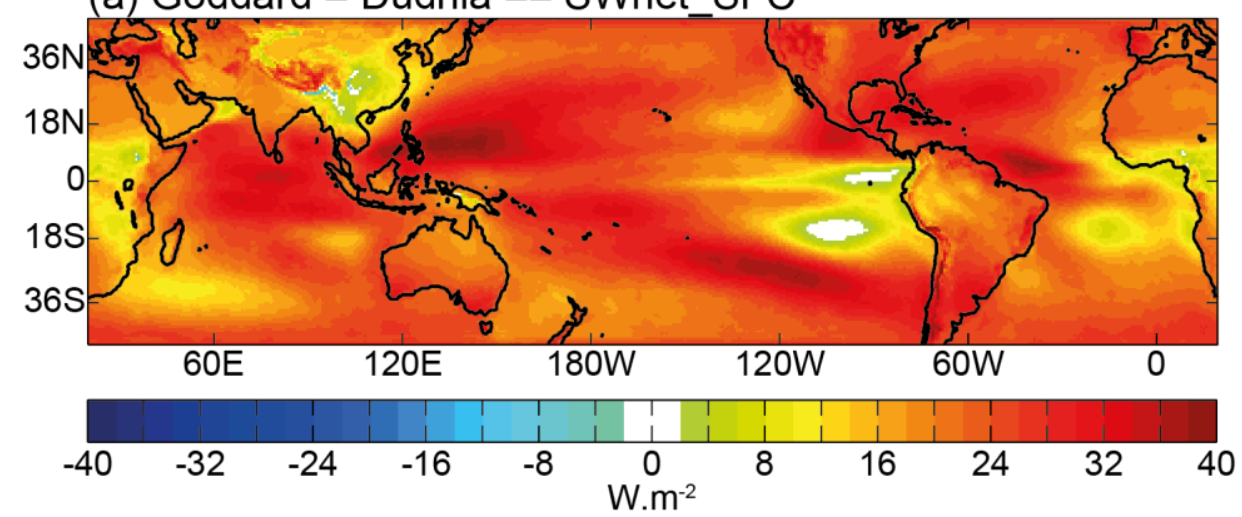

(b) Goddard - Dudhia -- Rainfall

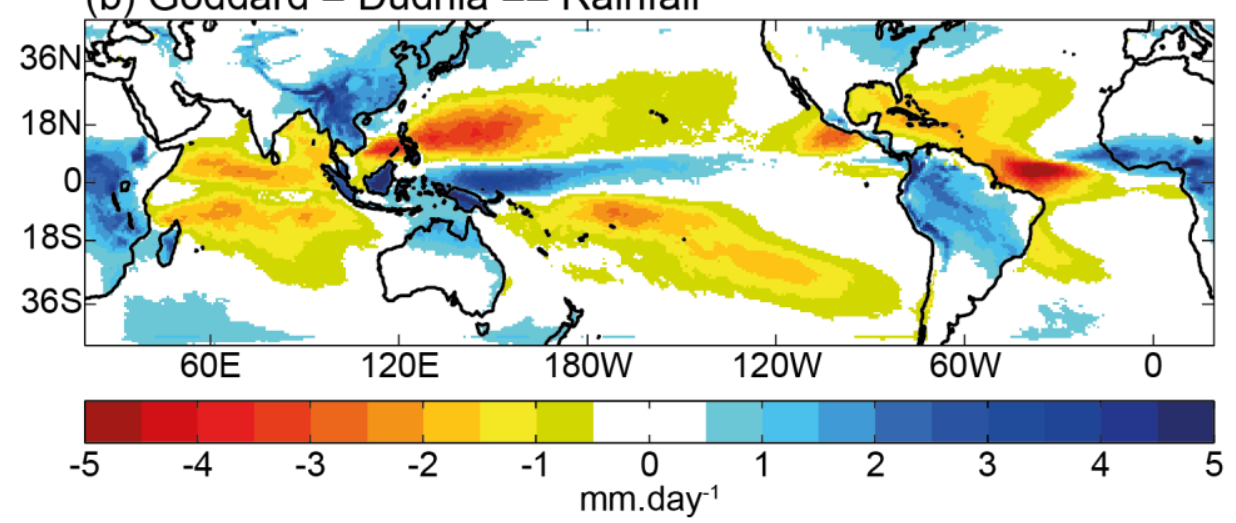

(c) Goddard - Dudhia -- Latent heat fluxes

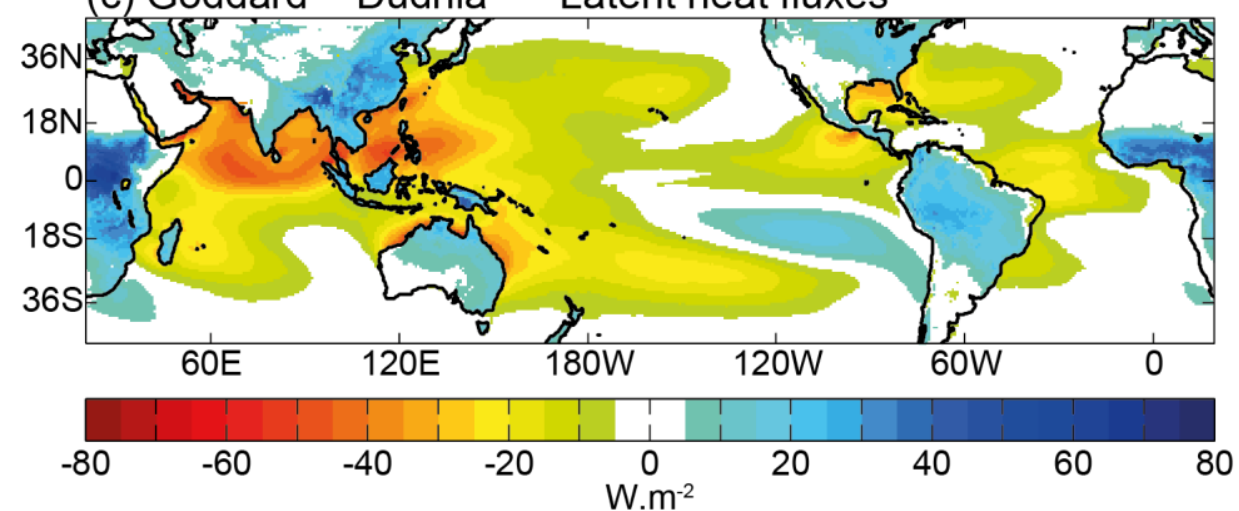

(d) Goddard - Dudhia -- Moisture fluxes \& convergence

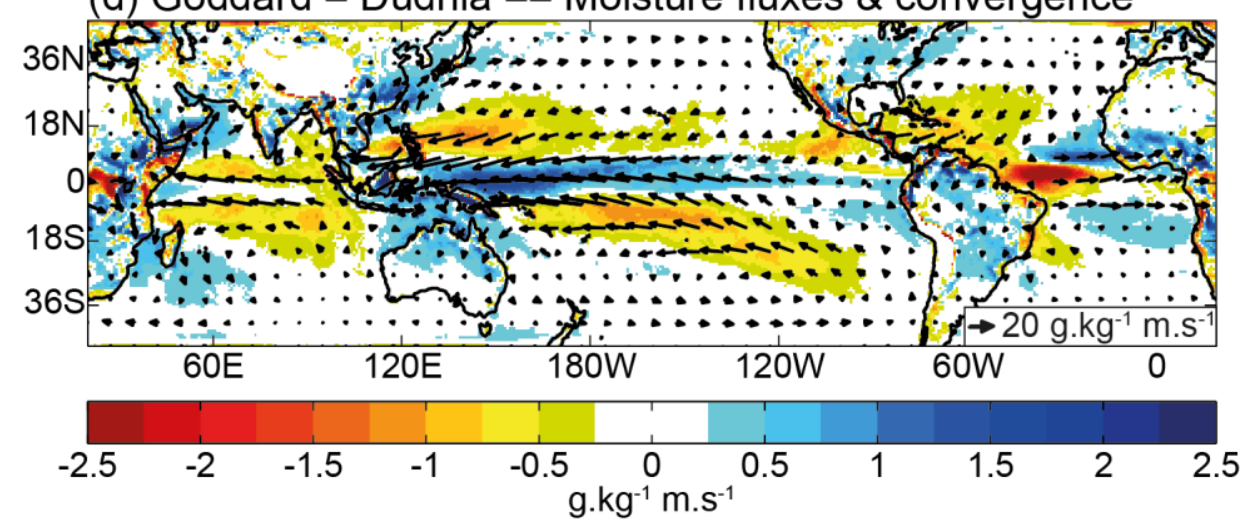

Figure 7: Differences in the annual mean climatology of (a) SWnet_SFC, (b) rainfall, (c) latent heat fluxes, and (d) 1000 to $700 \mathrm{hPa}$ vertically-averaged moisture fluxes (vectors) and moisture flux convergence (shadings) between the Goddard and Dudhia SW ensemble means from Set \#1. 
Potential temperature
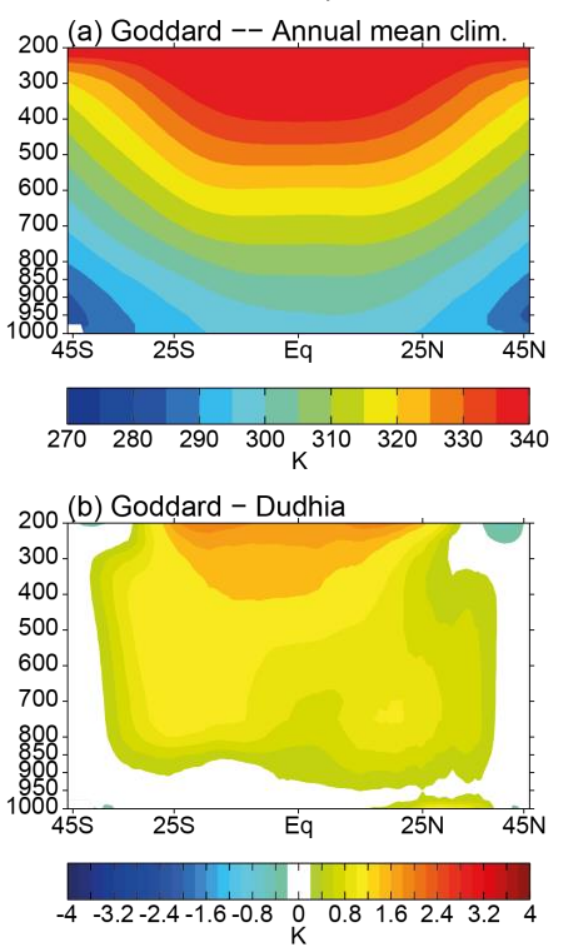

Vertical velocity

(c) Goddard -- Annual mean clim
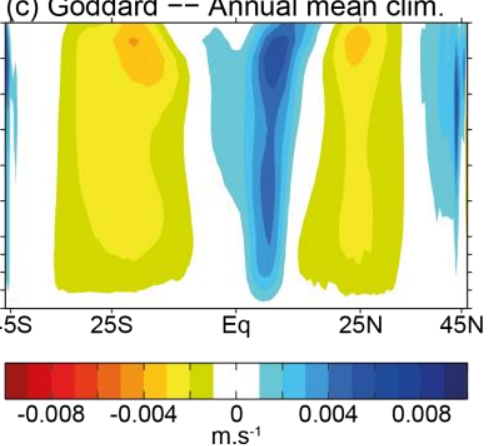

(d) Goddard - Dudhia

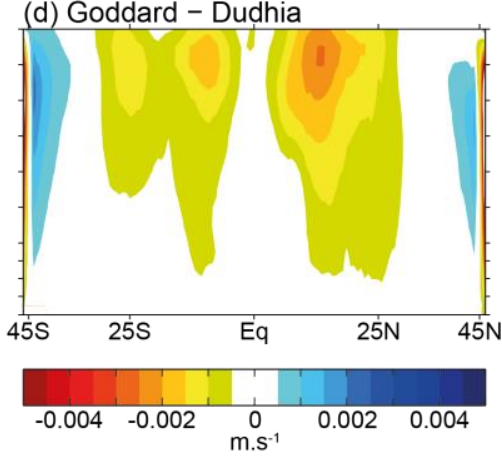

Cloud fraction

(e) Goddard -- Annual mean clim.
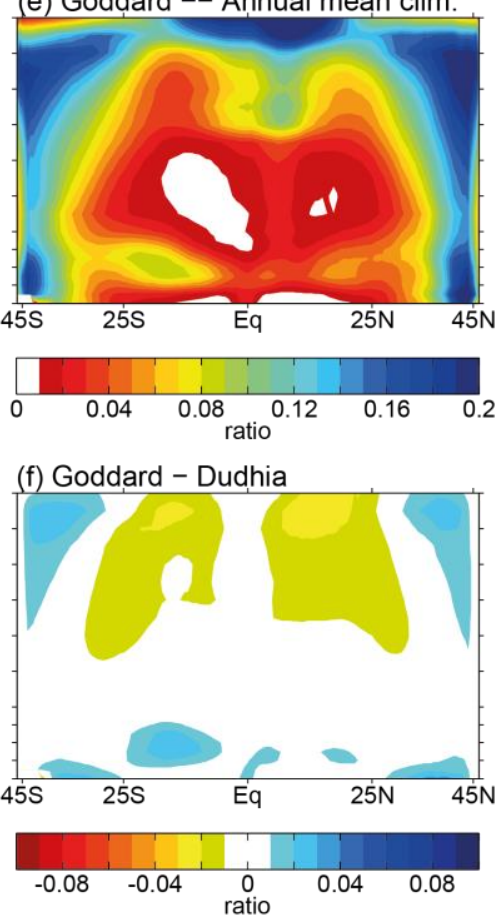

Figure 8:

(a) Vertical-meridional cross-section in the annual mean climatology of potential temperature $(\mathrm{K})$ averaged over sea points for the Goddard SW ensemble mean from Set \#1. (b) Differences between the Goddard and Dudhia SW ensemble means (contours every $0.2 \mathrm{~K})$. (c-d and e-f) Same as (a-b) but for vertical velocity $\left(\mathrm{m} \cdot \mathrm{s}^{-1}\right)$ and cloud fraction from the microphysics (ratio) with contours every $0.0005 \mathrm{~m} . \mathrm{s}^{-1}$ and 0.01 , respectively. In (c) and (d) positive velocity is upward. 


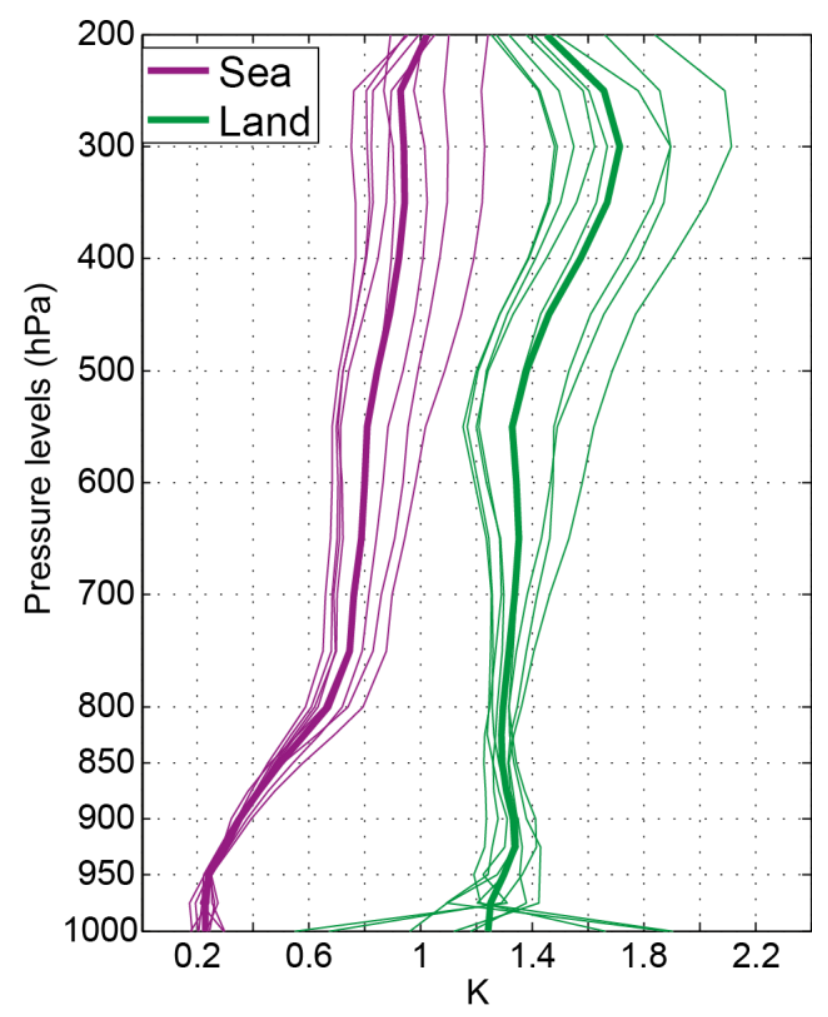

Figure 9: Differences in the vertical profile of the annual mean climatology of potential temperature averaged over sea (purple) and land (green) points between the Goddard and Dudhia SW ensembles from Set \#1. Solid lines show the differences between the 8 members of the Goddard and Dudhia SW ensembles. Bold lines show the differences between the two ensemble means. 
Goddard -- Annual mean

(a) $\theta$ tendencies due to SW

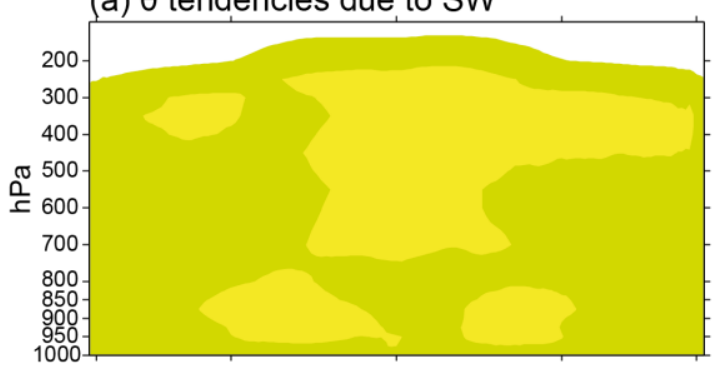

(b) $\theta$ tendencies due to LW

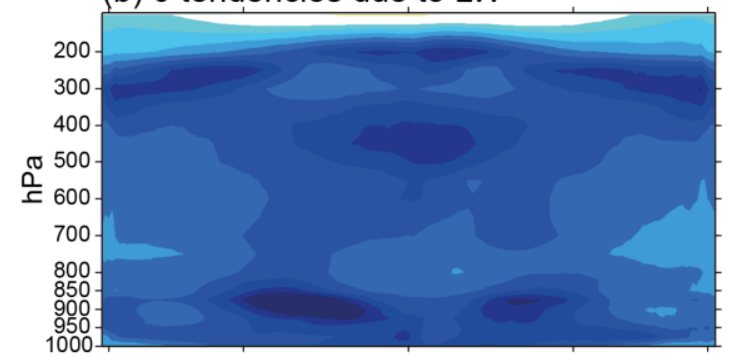

(c) $\theta$ tendencies due to $\mathrm{CU}$

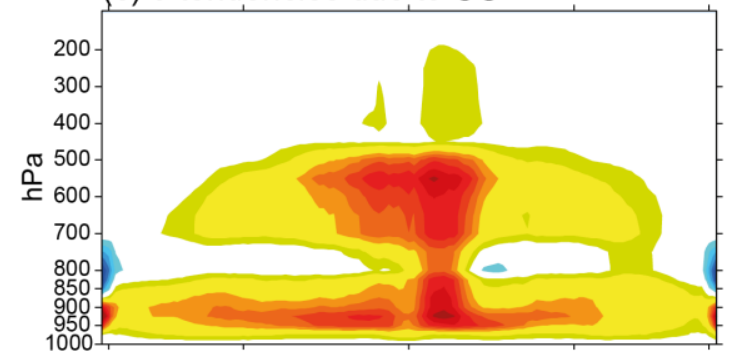

(d) $\theta$ tendencies due to MP

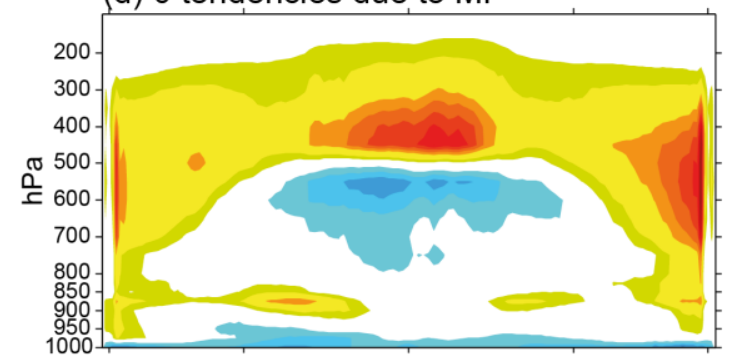

(e) $\theta$ tendencies due to $\mathrm{PBL}$
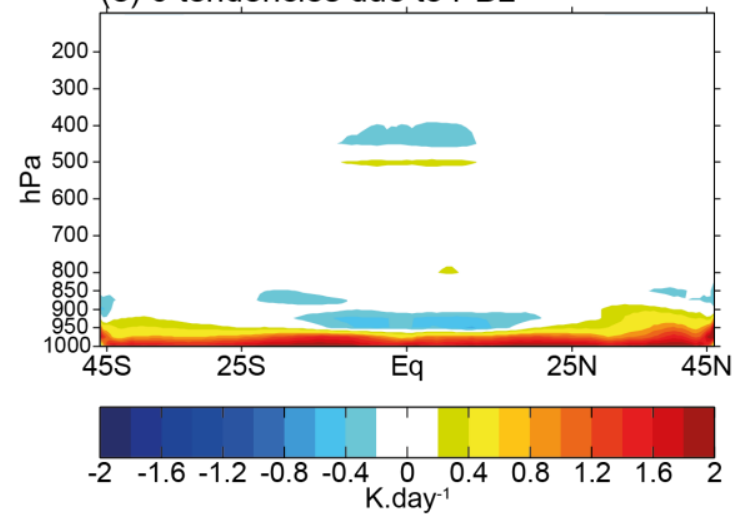

Goddard - Dudhia differences

(f) $\theta$ tendencies due to SW

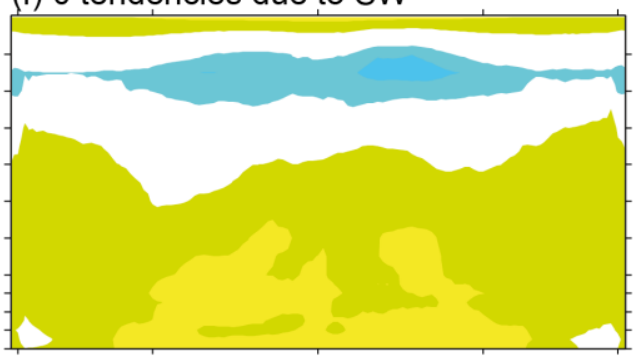

(g) $\theta$ tendencies due to LW

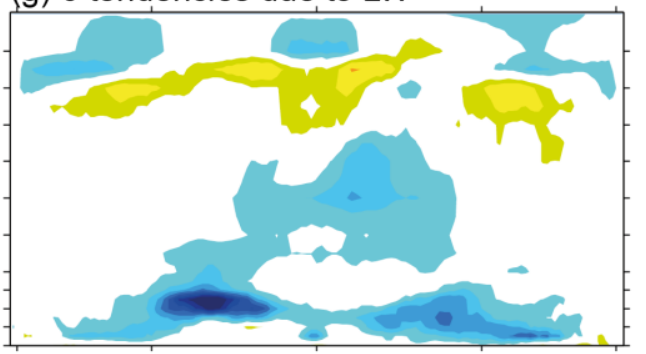

(h) $\theta$ tendencies due to $\mathrm{CU}$
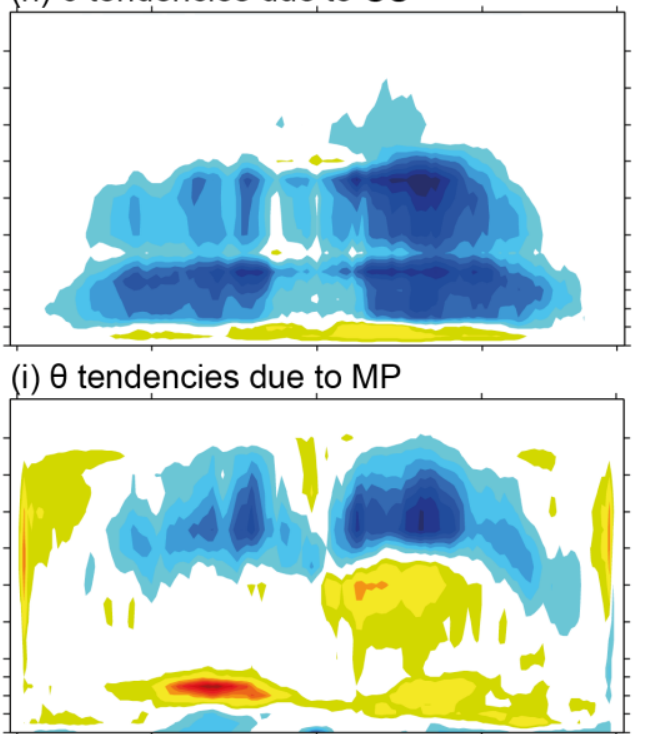

(j) $\theta$ tendencies due to PBL
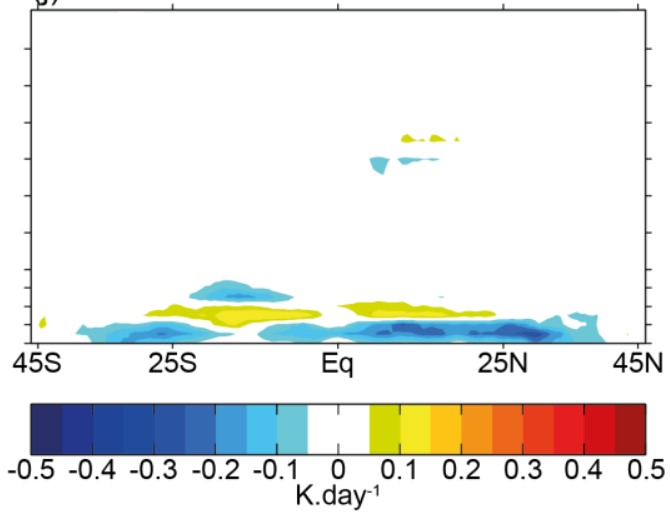

Figure 10: (a-e) Vertical-meridional cross-section of potential temperature tendencies due to the parameterization of SW, $\mathrm{LW}, \mathrm{CU}, \mathrm{MP}$, and PBL for the Goddard control simulation from Set \#3, respectively (see Table 1 for acronyms). Tendencies are accumulated at the daily timescale then averaged over the year 1989. (f-j) Same as (a-e) but for the differences between the Goddard and Dudhia control simulations from Set \#3. 
(a) Goddard - Dudhia scat1

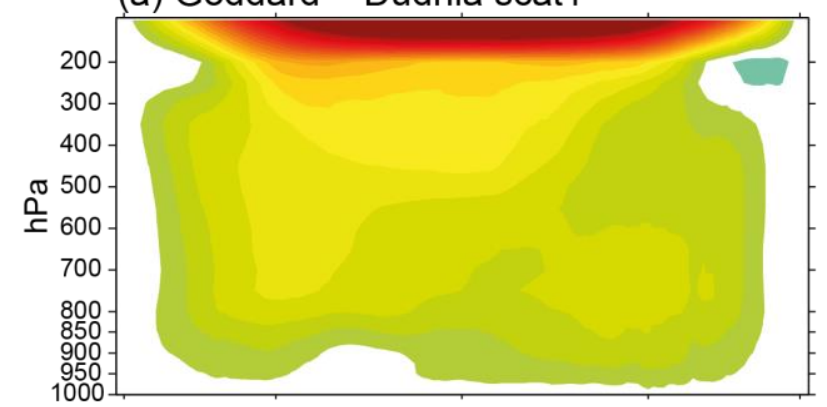

(b) Goddard - Goddard no O3 absorption

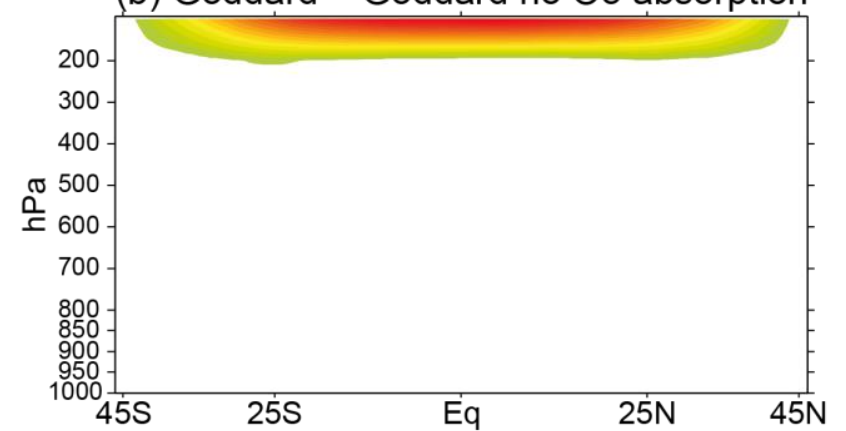

(c) Goddard - Dudhia scat0

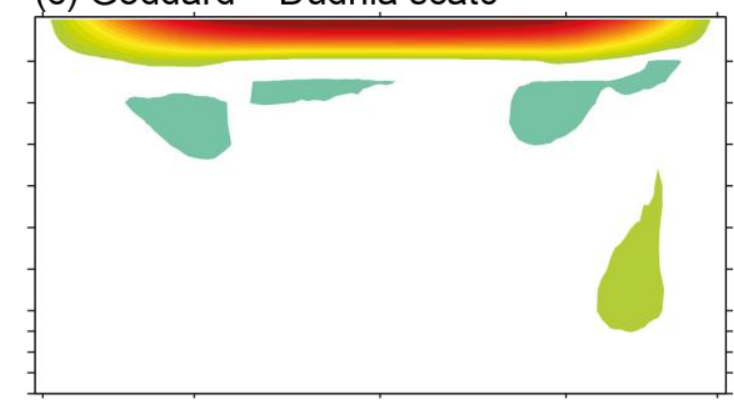

(d) Dudhia scat0 - Dudhia scat1
1033
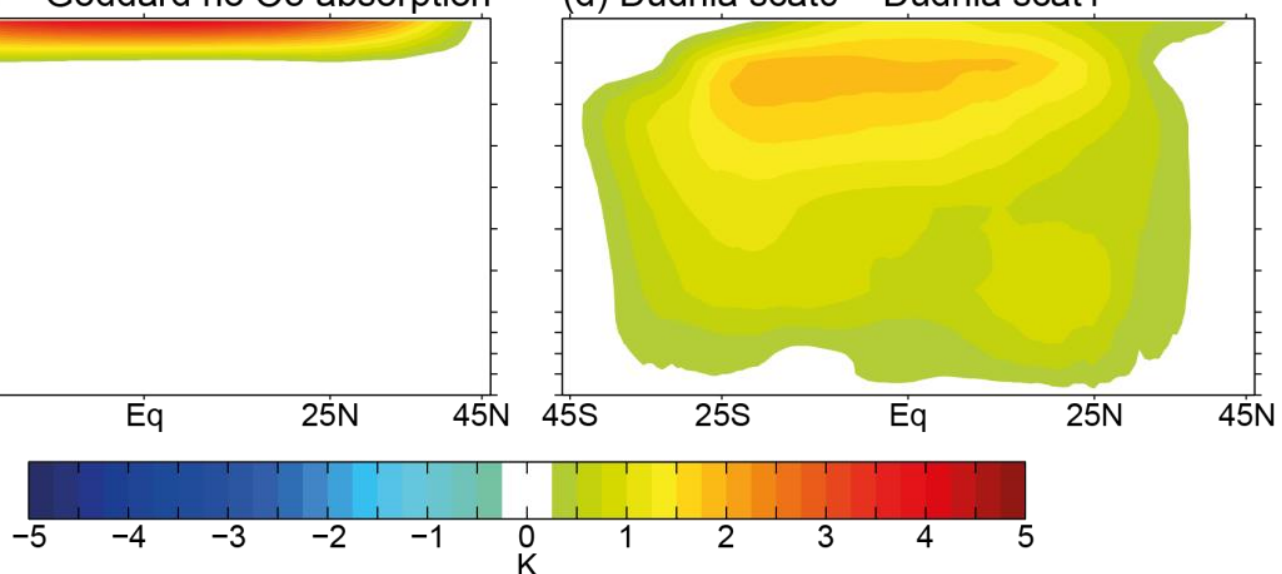

Figure 11: Vertical-meridional cross-section in the differences of potential temperature (K) between (a) the two control simulations from Set \#3, (b) the Goddard control simulation and that with no $\mathrm{O}_{3}$ absorption, (c) the Goddard control simulation and the Dudhia simulation with no scattering, and (d) between the Dudhia simulation with no scattering and the Dudhia control simulation. 
(a) Sea points

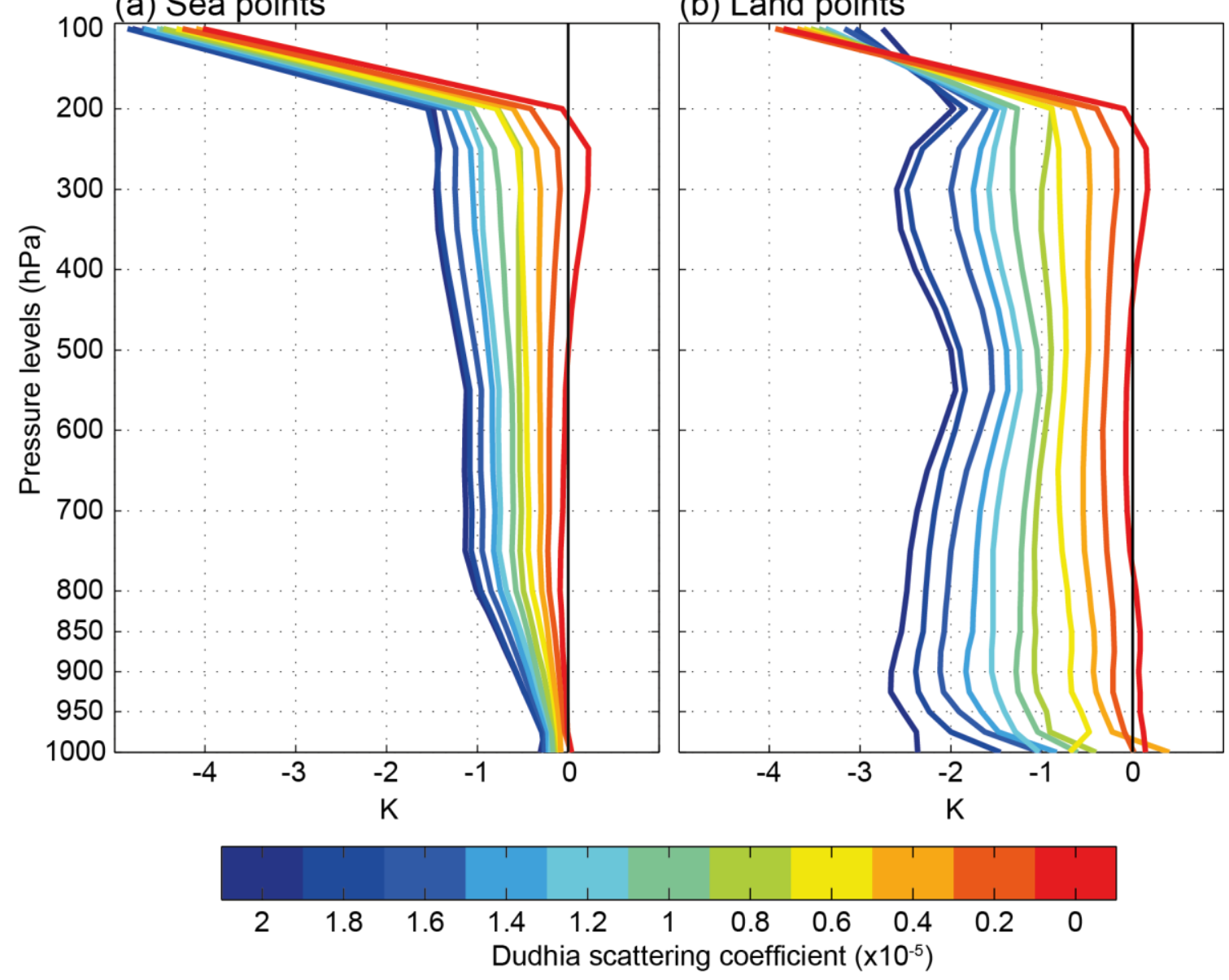

Figure 12: Differences in the vertical profile of annual mean potential temperature averaged over (a) sea and (b) land points between the Goddard control simulation and the 10 Dudhia simulations with the scattering coefficient varying from $2 \times 10^{-5}$ to 0 every $0.2 \times 10^{-5}$. The black line is zero difference. 
(a) SWnet_SFC

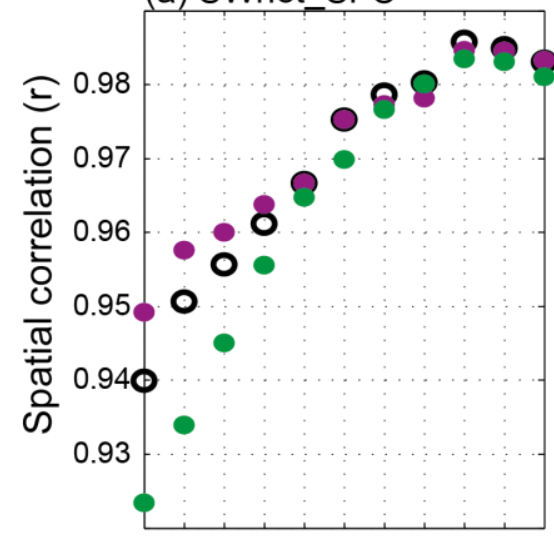

(d) SWnet_SFC $\left(W \cdot m^{-2}\right)$

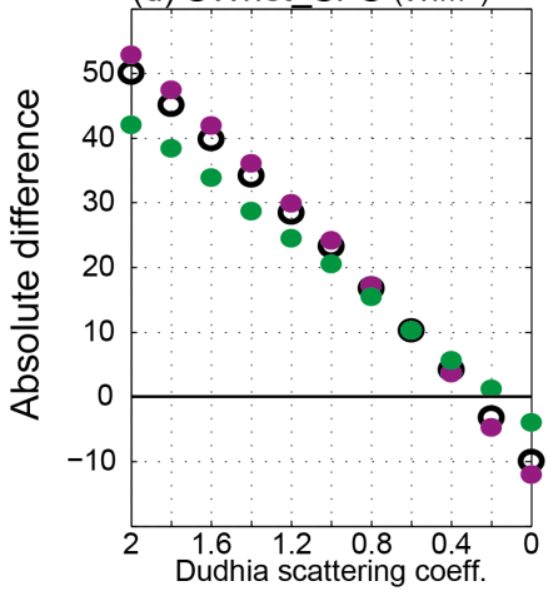

(b) Latent heat fluxes
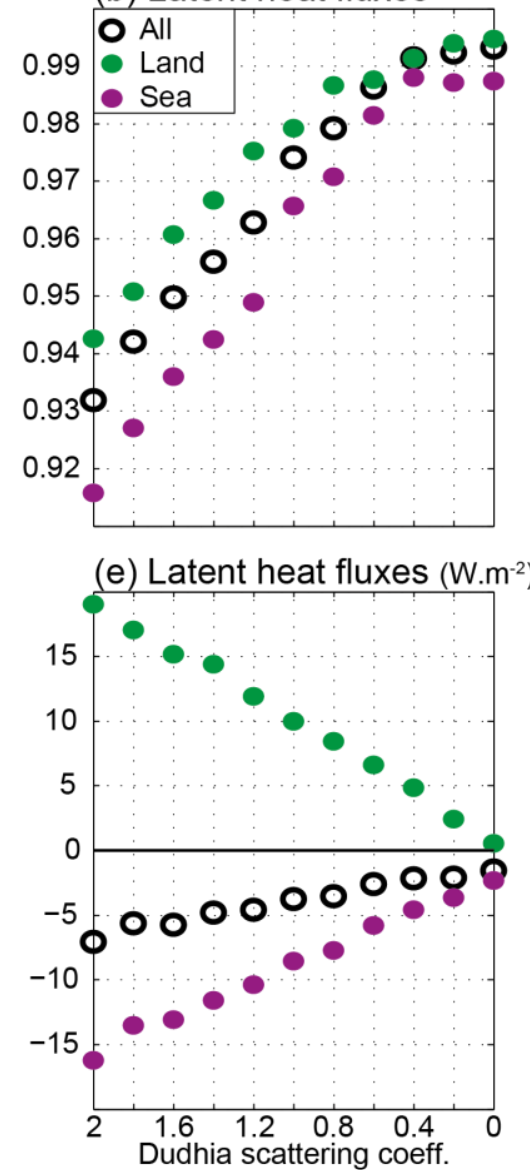

(c) Rainfall
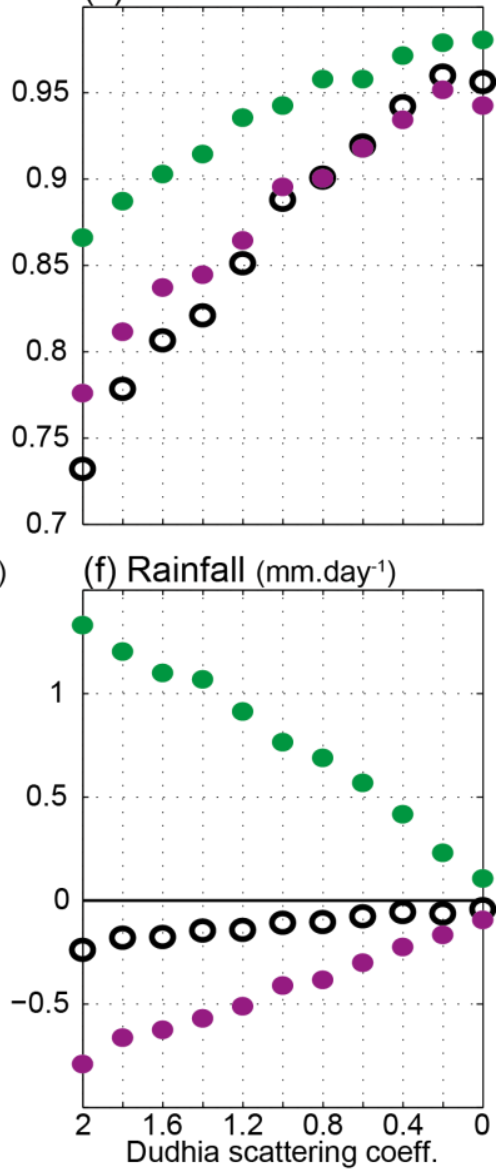

Figure 13: Spatial correlation in the annual mean (a) SWnet_SFC, (b) latent heat fluxes, and (c) rainfall between the Goddard control simulation and 10 Dudhia simulations with the scattering coefficient varying from $2 \times 10^{-5}$ to 0 every $0.2 \times 10^{-5}$. (d-f) Same as (a-c) but areaaveraged differences. Black circles correspond to all grid points within the tropical-channel domain. Green and purple dots denote land and sea points within the tropical-channel domain, respectively. 
(a) Spatial distribution

1054

1055

1056

1057 (b) Biases

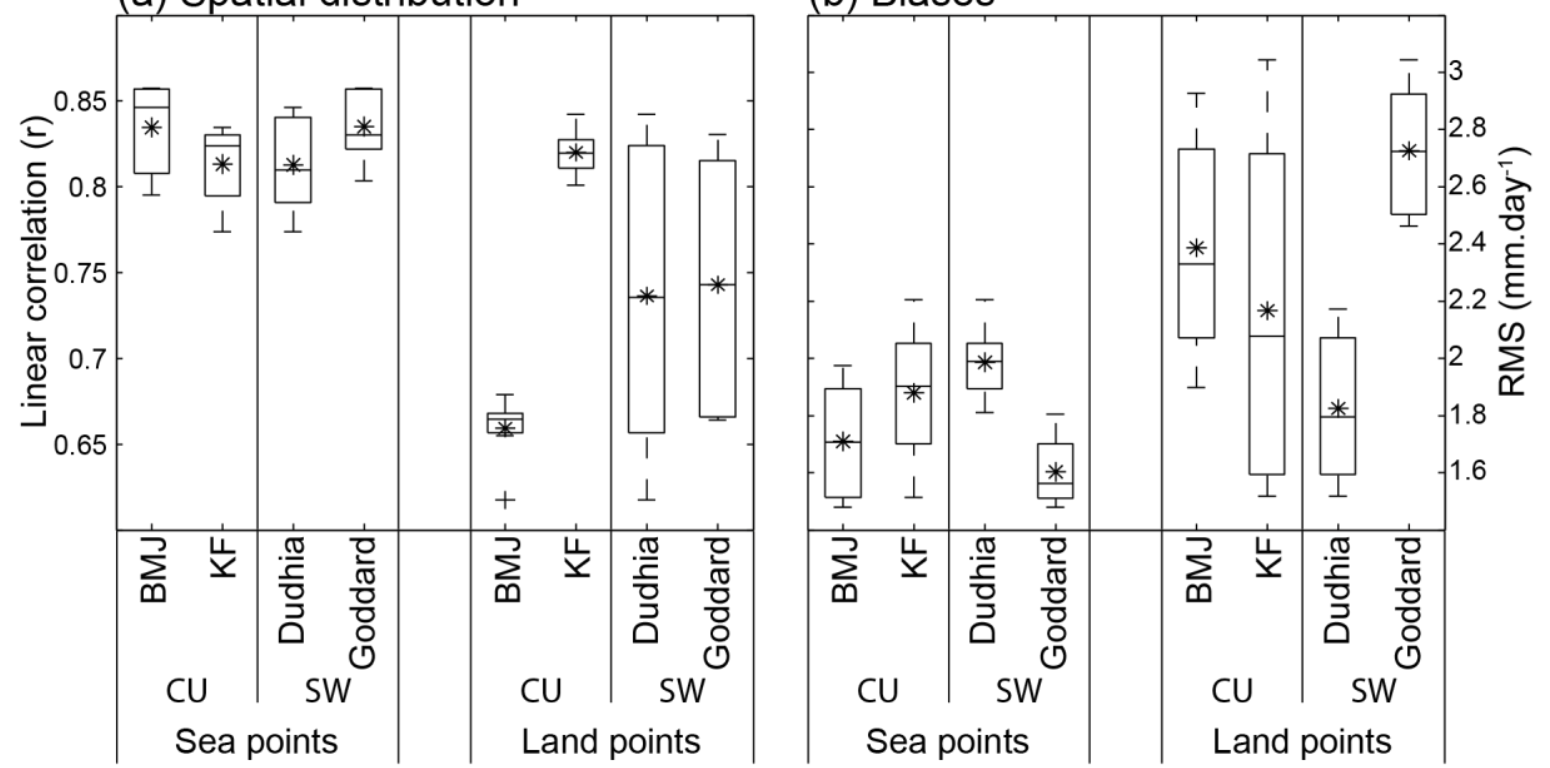

Figure 14: Same as Figs. 5d-g but for the two CU and SW ensembles. 
(a) Biases -- Sea points

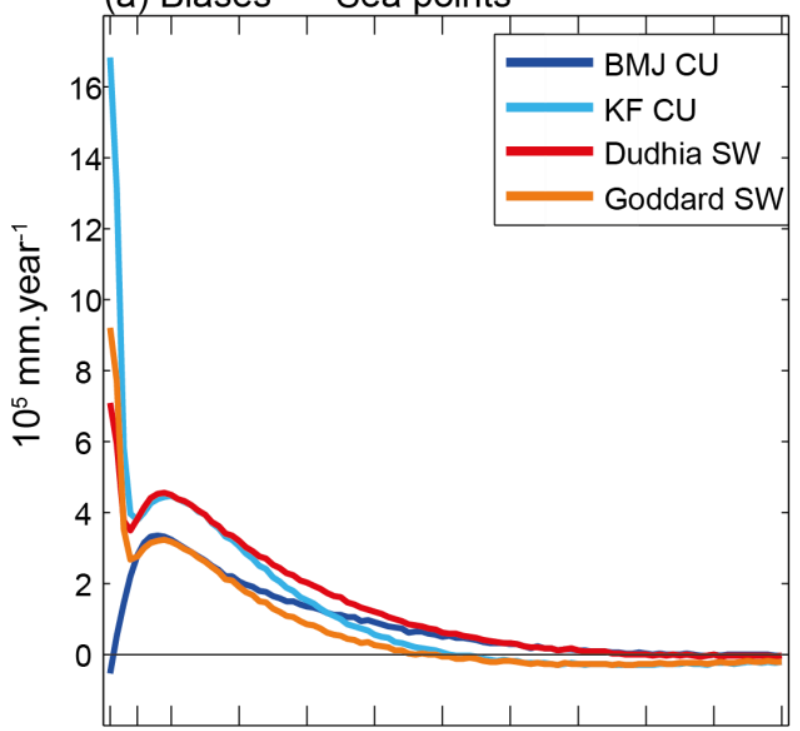

(c) Inter-member spread -- Sea points

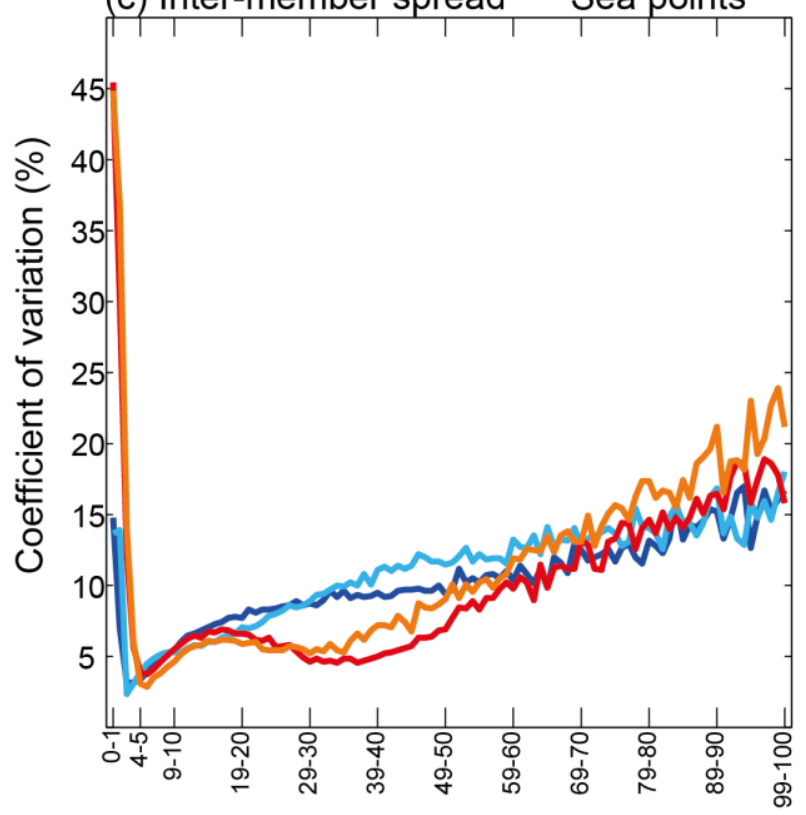

(b) Biases -- Land points

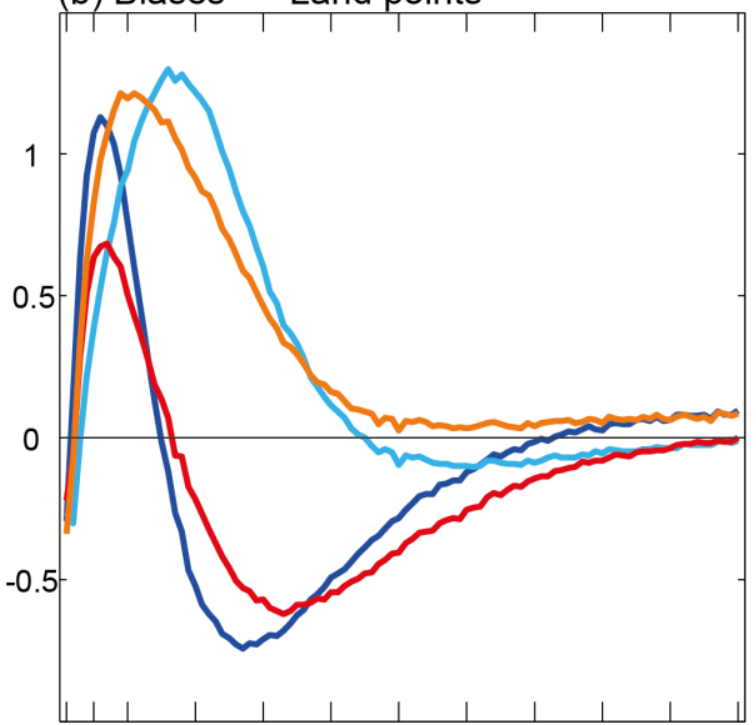

(d) Inter-member spread -- Land points

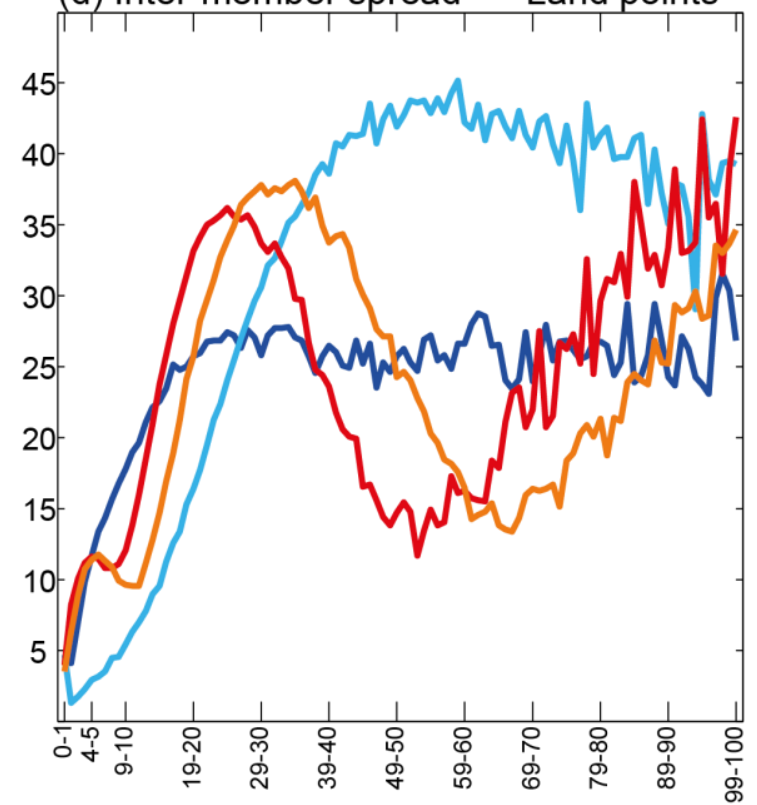

Figure 15: Biases of the two $\mathrm{CU}$ and $\mathrm{SW}$ ensemble means in rainfall amounts accumulated over (a) sea and (b) land points within the tropical-channel domain for the year 1989 according to daily rainfall intensity. Ranges of rainfall intensity vary from 0 to 100 mm.day ${ }^{-1}$, every 1 mm.day ${ }^{-1}$. Biases are computed against the TRMM climatology computed for the 1998 - 2007 period. (c-d) Same as (a-b) but for the coefficient of variation of each ensemble $(\%)$ computed as the ratio between the inter-member standard deviation and the ensemble mean. 